\title{
A NEW RHAMPHORHYNCHID PTEROSAUR FROM THE UPPER JURASSIC OF XINJIANG, CHINA, AND THE PHYLOGENETIC RELATIONSHIPS OF BASAL PTEROSAURS
}

\author{
BRIAN ANDRES, ${ }^{*}, 1$ JAMES M. CLARK, ${ }^{2}$ and XU XING ${ }^{3}$ \\ ${ }^{1}$ Department of Geology and Geophysics, Yale University, New Haven, Connecticut 06520, U.S.A., brian.andres@aya.yale.edu; \\ ${ }^{2}$ Department of Biological Sciences, George Washington University, Washington, D.C. 10024, U.S.A., jclark@gwu.edu; \\ ${ }^{3}$ Institute of Vertebrate Paleontology \& Paleoanthropology, Chinese Academy of Sciences, Beijing 100044, China, \\ xu.xing@pa.ivpp.ac.cn
}

\begin{abstract}
A new rhamphorhynchid pterosaur species, Sericipterus wucaiwanensis, gen. et sp. nov., is described from the Upper Jurassic part of the Shishugou Formation in the Xinjiang Autonomous Region of northwest China. Pterosaurs from this unit are the earliest and only records of pterosaurs in the Jurassic of northwest China. The individual specimen is one of the largest known among 'rhamphorhynchoids,' or non-pterodactyloid pterosaurs. The holotype comprises an associated skeleton of mostly disarticulated, largely three-dimensional material. Although partly crushed, the preservation in this specimen reveals morphology rarely seen in non-pterodactyloid pterosaurs. This includes a distinct cervical intervertebral articulation morphology that is proposed to be widespread among the non-pterodactyloids. The skull of this new specimen is most similar to that of other rhamphorhynchids, Angustinaripterus longicephalus and Harpactognathus gentryii, found in terrestrial deposits. A phylogenetic analysis of 18 non-pterodactyloid pterosaurs and the Pterodactyloidea places Sericipterus wucaiwanensis with these species within the Rhamphorhynchinae and a monophyletic Rhamphorhynchidae. Unlike previous phylogenetic analyses, the Dimorphodontidae is paraphyletic, the Campylognathoididae is polyphyletic, and the Anurognathidae is the sister group of the Pterodactyloidea. Sericipterus wucaiwanensis, Angustinaripterus longicephalus, Harpactognathus gentryii represent a clade of large pterosaurs that likely lived in the terrestrial settings in which they preserved.
\end{abstract}

\section{INTRODUCTION}

From 2001 to 2006, joint paleontological expeditions from the Institute of Vertebrate Paleontology and Paleoanthropology, Beijing, and The George Washington University, Washington, D.C., surveyed the Junggar Basin of the Xinjiang Autonomous Region, People's Republic of China. The most productive fossil vertebrate locality found during these annual expeditions has been the Wucaiwan area in the eastern part of the Junggar Basin (Fig. 1). Here, the remains of the basal tyrannosauroid Guanlong wucaii (Xu et al., 2006b), ceratosaurs (Xu et al., 2009), a giant theropod (Xu and Clark, 2008), the basal ceratopsian Yinlong downsi (Xu et al., 2006a), the stegosaur Jiangjunosaurus junggarensis (Jia et al., 2007), tritylodonts, and multiple crocodylomorphs such as the 'sphenosuchian' Junggarsuchus sloani (Clark et al., 2004a) were excavated from the Shishugou Formation. Three pterosaur specimens have also been reported from the same area and formation (Andres and Clark, 2005), the most complete of which is described here.

Pterosaurs have already been reported from Xinjiang but, previously, were confined to the Lower Cretaceous Tugulu Group (Young, 1964, 1973; Buffetaut, 1996; Maisch et al., 2004). These include the species Dsungaripterus weii Young, 1964, Noripterus complicidens Young, 1973, and Lonchognathosaurus acutirostris Maisch et al., 2004, which is likely an individual of Dsungaripterus weii (B. Andres, pers. observ.). The pterosaur discoveries from the Wucaiwan locality are the earliest and only record of Jurassic pterosaurs from Xinjiang and one of only a handful of Jurassic pterosaur localities from China. The new specimens include a 'rhamphorhynchoid,' or non-pterodactyloid pterosaur, that is described here, an isolated wing phalanx from the upper part of the

\footnotetext{
${ }^{*}$ Corresponding author
}

Shishugou Formation, and a fragmentary pterodactyloid from the lower part of the same formation.

Traditional classifications (e.g., Wellnhofer, 1978) divided pterosaurs into two suborders: the primitive long-tailed "Rhamphorhynchoidea,"and the derived short-tailed Pterodactyloidea. The "Rhamphorhynchoidea" has been shown to be paraphyletic with respect to the Pterodactyloidea (e.g., Howse, 1986; Kellner, 2003; Unwin, 2003a). Therefore, in phylogenetic literature it has been informally termed non-pterodactyloid pterosaurs (e.g., Jensen and Padian, 1989; Andres and Ji, 2006).

The Wucaiwan non-pterodactyloid pterosaur is described here, named Sericipterus wucaiwanensis, gen. et sp. nov., compared to the rhamphorhynchids, and its phylogenetic relationships to the other basal pterosaurs are delineated. The new specimen presents sufficient morphology to be described, diagnosed as a new species, and used to help determine the phylogenetic relationships of the non-pterodactyloid pterosaurs. It is compared to the other taxa identified as rhamphorhynchids in the phylogenetic analysis: Angustinaripterus longicephalus $\mathrm{He}$ et al., 1983, from the Middle Jurassic of central China, Harpactognathus gentryii Carpenter et al., 2003, from the Upper Jurassic of Wyoming, Rhamphorhynchus muensteri (sensu Bennett, 1996) and Scaphognathus crassirostris Wagner, 1861, from the Upper Jurassic of Germany, Cacibupteryx caribensis Gasparini et al., 2004, from the Upper Jurassic of Cuba, and Dorygnathus banthensis Theodori, 1830, from the Lower Jurassic of Germany.

\section{MATERIALS AND METHODS}

The skeleton is described in anatomical position of the wings outstretched laterally as they would be in flight. Therefore, what might be termed the medial and lateral aspects of the more proximal wing bones are instead referred to as the ventral and dorsal aspects, respectively. The anatomical directions of mesial 




FIGURE 1. Locality of Sericipterus wucaiwanensis holotype (arrow), upper part of Shishugou Formation in the Wucaiwan area. Viewed from the southeast. and distal are used for orientating along the jaw margins as opposed to anterior and posterior, respectively (e.g., Unwin, 2003a). Muscle scars in the appendicular skeleton are identified with respect to the attachments recognized by Bennett (2003) in Campylognathoides liasicus.

The procedure of calculating wingspans is taken from Bennett (2001b), which consists of summing of the lengths of the forelimb bones excluding the carpus and then multiplying by a factor of two. The omission of the width across the pectoral girdle and the carpus is intended to offset the flexures along the wing in the total wingspan. This is a repeatable and conservative method to calculate wingspans, which have tended to be reported as larger in the literature.

The wings of Sericipterus are missing the wing metacarpals as well as having incomplete radii/ulnae and third wing phalanges. A minimum wingspan estimate of $1.73 \mathrm{~m}$ was calculated by summing the lengths of the complete wing bones, the estimated minimum length of the third wing phalanx, and the estimated length of the missing radius/ulna and wing metacarpal. The left and right third wing phalanges are missing their proximal and distal ends, respectively, so that it is not possible to ascertain the total length of these elements. The more complete of these two phalanges, the left phalanx, is missing its proximal end, which through comparison with the proximal expansion of right phalanx would add a minimum of $30 \mathrm{~mm}$ to its length. The length of the radius/ulna and the wing metacarpal were calculated from the average ratio of these bones to the humerus in Rhamphorhynchus muensteri, the species most closely related to Sericipterus with a completely preserved wing skeleton in the analysis. All measurements were made using a pair of Mitutoyo calipers, accurate to $0.02 \mathrm{~mm}$.

The results of 20 phylogenetic analyses of pterosaur intrarelationships have been published at the time of acceptance, 15 with published data matrices (Howse, 1986; Bennett, 1989, 1994, 2007; Unwin, 1992, 1995, 2002, 2003a, 2003b; Unwin and Lü, 1997; Viscardi et al., 1999; Kellner, 2003, 2004; Maisch et al., 2004; Wang et al., 2005, 2008; Lü and Ji, 2006; Martill and Naish, 2006; Andres and Ji, 2008; Lü et al., 2008). Only eight of these analyses have addressed the relationships of the basal pterosaurs. Characters, codings, and terminal taxa from this previous work were integrated into this analysis and were recoded as little as possible to provide a consensus of previous work. Inapplicable character states were reductively coded. In other words, characters dependent on the presence of a particular state in another character were coded as missing data for taxa in which the particular state is absent (i.e., a character complex). Inapplicable states are marked by a dash $(-)$, which phylogenetic analysis programs treat the same as missing data (Strong and Lipscomb, 2000). Parsimony uninformative characters were omitted resulting in a list of 75 characters (Appendix 1). Eighteen non-pterodactyloid species including Sericipterus wucaiwanensis, the three outgroups used by Wang et al. (2005), and a supraspecific taxon representing the Pterodactyloidea were used as terminal taxa. The character states for the Pterodactyloidea were obtained by optimizing the characters of this analysis to the base of the Pterodactyloidea on the topology recovered by Andres and Ji (2008). Characters with ambiguous optimizations were coded as polymorphic for this taxon.

The character matrix (Appendix 2) was analyzed using PAUP*4.0 b10 (Swofford, 2003) both with and without ambiguous branch support (amb and amb- parsimony options, respectively). Tree searches included a Branch-and-Bound search and 10,000 random addition-sequence Tree-BisectionReconnection heuristic searches. All characters were unordered and equally weighted (Fitch optimality criterion). Bootstrap and Bremer support values were generated using the same settings as the heuristic parsimony analysis. Tree lengths and tree scores were calculated in PAUP*, and the index file for calculating Bremer support values in PAUP* was generated in MacClade 4.07 (Maddison and Maddison, 2005).

\section{SYSTEMATIC PALEONTOLOGY \\ PTEROSAURIA Owen, 1842 \\ RHAMPHORHYNCHIDAE Seeley, 1870 \\ RHAMPHORHYNCHINAE SENSU Unwin, 2003a SERICIPTERUS, gen. nov.}

Type Species-Sericipterus wucaiwanensis, sp. nov. Diagnosis - As for type and only species. 
Etymology-The generic name is based on the Latin word sericum (L.), meaning silk in reference to the ancient Silk Road that passed through what is now the Xinjiang Autonomous Region, and pteros (Gr.), meaning wing, a traditional ending for pterosaur names.

\section{SERICIPTERUS WUCAIWANENSIS, sp. nov.}

(Figs. 2-6)

Holotype-IVPP V14725 (Institute of Vertebrate Paleontology and Paleoanthropology, Beijing, People's Republic of China): an incomplete skeleton including a disarticulated skull; partial mandible; at least 12 isolated teeth; partial vertebral column (six cervicals, nine dorsals, two sacrals); the right scapula and coracoid; both humeri; the ends of the right ulnae and radii; the distal end of the left ulna; a proximal manual phalanx; the left first, right second, both third, and both fourth wing phalanges; an ischiopubic plate; two metapodial elements, and a probable pedal phalanx fragment.

Etymology-The specific name is derived from the Wucaiwan area in which this pterosaur was found. In Chinese it means 'fivecolor bay' and refers to the striking variegated colors of the rocks in the area (Fig. 1).

Distribution-Alluvial facies of the Upper Shishugou Formation, between tuffs dated at $161.2 \pm 0.2 \mathrm{Ma}$ and $158.7 \pm 0.3 \mathrm{Ma}$ (Clark et al., 2006), equivalent to the Oxfordian, Upper Jurassic; Wucaiwan locality, eastern Junggar Basin, Xinjiang Autonomous Region, People's Republic of China.

Diagnosis-Largest rhamphorhynchid with a wingspan of at least $1.73 \mathrm{~m}$. Apomorphies in comparison with other nonpterodactyloid pterosaurs: terminal rostral expansion includes only two pairs of teeth; nasal process of the maxilla with T-shaped cross-section; large, U-shaped quadratojugal has broad contact with the ventral margin of the skull; large lateral processes of the parietals abut the postorbital processes of frontals; low parietal crest extending most of length of parietal; transverse crest at frontoparietal contact; scapula length subequal to coracoid; wing phalanges with oval cross-section twice as wide as deep; expanded ends of first and second wing phalanges wider than twice their mid-width; fourth wing phalanx slightly longer than second wing phalanx; enlarged metatarsals with subterminal distal condyles.

\section{DESCRIPTION}

IVPP V14725 is a partial skeleton preserved over a one-half by one-quarter-meter area and collected in a single field jacket (Fig. 2). The specimen is disarticulated save for bones of the braincase and the dorsal and sacral vertebral series. The specimen was removed from the surrounding matrix with the exception of the bones of the braincase and temporal region of the skull for which full preparation would have undermined physical integrity of these elements. The quality of preservation of the individual bones varies greatly over the specimen. It was found on a deflated surface so that the skeletal elements are all in some manner crushed, broken, or fractured; however, the texture of the bone is generally well preserved and most elements are three-dimensional. This type of preservation is more typical of pterosaur specimens recovered from terrestrial sediments, instead of the thinly bedded lagerstätten that preserve the majority of pterosaur specimens.

\section{Ontogeny}

This individual is considered to be an osteological sub-adult because most but not all of the elements known to fuse during ontogeny of pterosaurs remain unfused in this specimen. Sutures are not visible between some elements of skull whereas others have become disarticulated. In the postcranium, the scapula and cora-
TABLE 1. Measurements of the skull elements of IVPP V14725 (in $\mathrm{mm})$.

\begin{tabular}{|c|c|c|}
\hline Element & Left & Right \\
\hline Preserved rostrum length & \multicolumn{2}{|c|}{$>146.8$} \\
\hline Preserved braincase length & \multicolumn{2}{|c|}{$>54.0$} \\
\hline $\begin{array}{l}\text { Skull length anterior to external } \\
\text { naris }\end{array}$ & \multicolumn{2}{|c|}{$\sim 63.2$} \\
\hline $\begin{array}{l}\text { Skull height at anterior margin of } \\
\text { external naris }\end{array}$ & \multicolumn{2}{|c|}{36.0} \\
\hline Skull maximum width & \multicolumn{2}{|c|}{$\sim 58.5$} \\
\hline External nares length & $>45.9$ & $>50.6$ \\
\hline External nares height & - & 9.1 \\
\hline Antorbital fenestra length & $>28.6$ & $>34.1$ \\
\hline Antorbital fenestra height & $>15.3$ & $>29.9$ \\
\hline Tooth row length & $>84.1$ & \\
\hline Mandible length & $>113.2$ & $>146.4$ \\
\hline
\end{tabular}

$-=$ missing element; $>=$ preserved length $;=$ approximate.

coid, sacral ribs, and the extensor tendon process of the first wing phalanx remain unfused. Some neural arches of dorsal vertebrae are separated from their lateral lamina, suggesting incomplete fusion between centra and the neural arches. However, sutures are not visible on the more complete dorsal or any other vertebrae.

\section{Skull}

The skull of IVPP V14725 is preserved as two distinct accumulations and approximately 18 isolated tooth fragments that could represent a minimum of 12 distinct teeth (Figs. 2-4; Table 1). The rostrum is detached from the posterior region of the skull and split into left and right halves just distal to the tip of the rostrum on the left side (Fig. 3). These have come to lie upon the right jugal and the left quadrate, respectively. The preserved posterior region of the skull includes the braincase, several of the temporal bones, and the right quadrate (Fig. 4), as well as most of the right and the posterior half of the left mandible (Fig. 1). The skull likely broke into anterior and posterior regions, and subsequently the rostrum split into two halves with the jugal and quadrate coming to lie between them. The degree of disarticulation of the skull is unusual for pterosaurs and reveals aspects of the skull not normally visible. The nasal process of the left maxilla is the posterior extent of the preserved rostrum, whereas the anterior extent of the preserved braincase is the orbit dorsal margin. These two extremities would flank the ascending process of the jugal. Summing the length of the preserved rostrum, braincase, and width of the ascending process of the jugal provides a minimum skull length estimate of about $210 \mathrm{~mm}$. The missing portions of the frontals, prefrontals, lacrimals, nasals, and maxillae would have to occupy only five $\mathrm{mm}$ for this skull to be larger than the previously largest known non-pterodactyloid skull, present in Dimorphodon macronyx Buckland 1829 (Wellnhofer, 1978).

Rostrum - The two halves of the rostrum were found lying on their lateral surfaces (Fig. 2). They are highly fractured, especially at their posterior ends where they have been eroded. Collectively, they preserve the anterior ends of the external narial and antorbital fenestrae, jugal and nasal processes of the maxillae, maxillary process of the left jugal, and the premaxillary bar.

The left rostral fragment is more complete than the right and was found associated with part of the right jugal (Fig. 3AB). It includes the premaxillary bar, the anterior-most end of the right half of the rostrum, and the anterior end of the maxillary process of the left jugal. The left half of this fragment preserves the anterior portions of the left external naris, antorbital fenestra, the jugal and nasal processes of the maxilla, and up to four alveoli. A small, attached fragment of the right rostrum preserves the first two right alveoli. The anterior end of the maxillary process of 

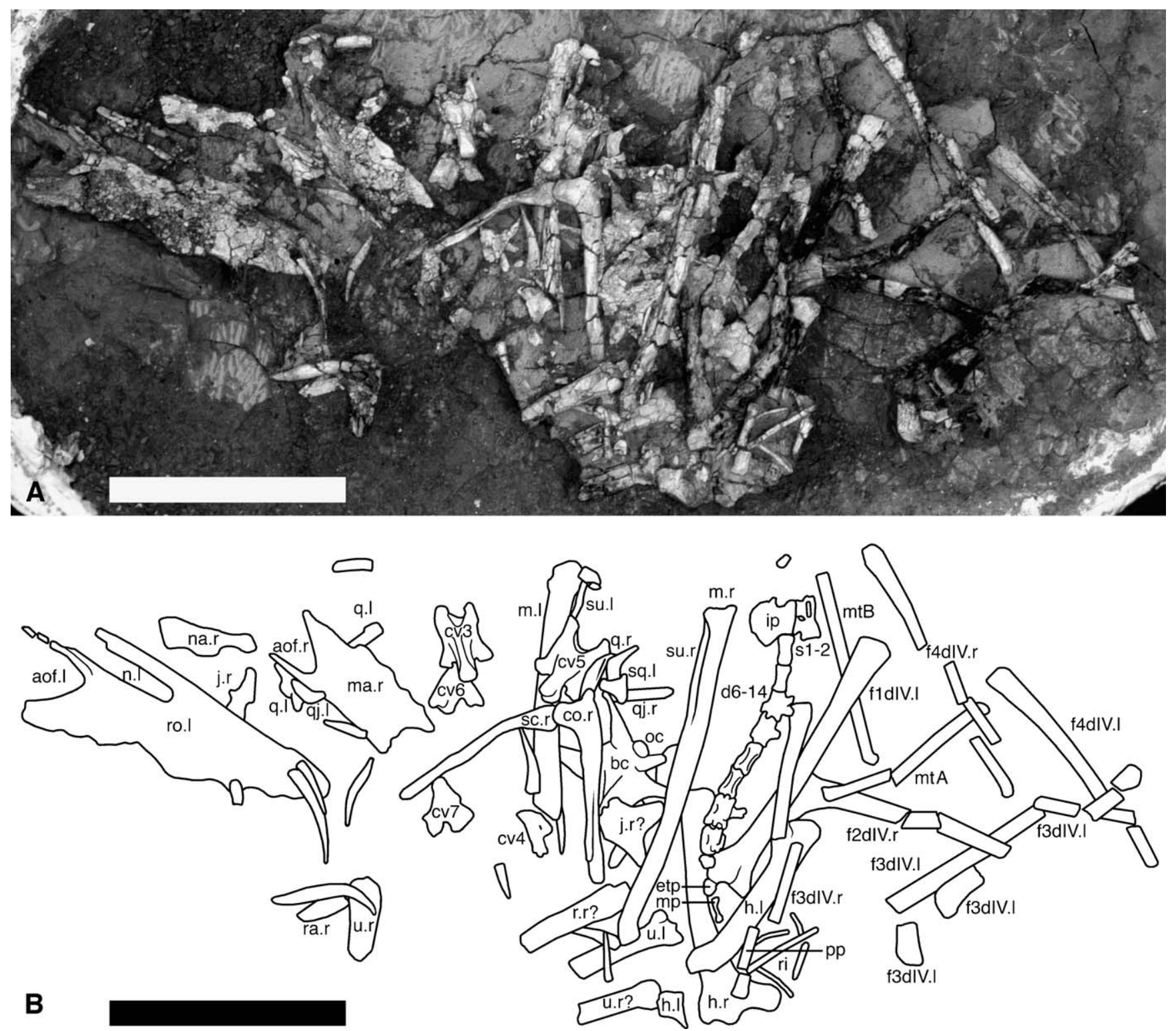

FIGURE 2. Sericipterus wucaiwanensis, gen. et sp. nov. (IVPP V14725). A, photograph; B, line drawing illustrating the arrangement of skeletal elements as they were collected. Teeth are not labeled. Abbreviations: aof, antorbital fenestra; bc, braincase; co, coracoid; cv, cervical vertebra; d, dorsal vertebra; etp, extensor tendon process of the first wing phalanx; fXdY, phalanx X of digit Y; $\mathbf{h}$, humerus; ip, ischiopubic plate; j, jugal; $\mathbf{m}$, mandible; ma, maxilla; mp, manual phalanx; mt, metatarsal; n, external naris; na, nasal; oc, occipital condyle; pp, pedal phalanx; q, quadrate; qj, quadratojugal; ra, radius; ri, ribs; ro, rostrum; s, sacral vertebra; sc, scapula; sq, squamosal; su, surangular; u, ulna; X.I, left element; and X.r, right element. Teeth are not labeled. Scale equals $10 \mathrm{~cm}$.

the left jugal was found articulated with the left maxilla but was removed in Figure 3. The right rostral fragment is less crushed and preserves presumably only the right maxilla (Fig. 3C). The ventral margin of the external naris, the anterior end of the antorbital fenestra, and the nasal process of the maxilla that separates these two openings dominate the preserved morphology. A skull fragment located between the halves of the rostrum is identified as the right nasal (Fig. 2).

The preserved portions of the anterior skull outline an elongate rostrum. The premaxillae are fused along their preserved lengths. The anterior tip of the skull bears a laterally compressed rostral process. This process projects anteriorly from the midline of the skull and is missing its tip to reveal an elliptical cross- section in anterior view. The preserved portion of the process is rather short, has a depth twice its width, and does not seem to taper. The process connects posteriorly with a low sagittal crest extending along the dorsal midline of the rostrum. The crest extends for half a centimeter before it is broken off and continues posteriorly as a broken base. Posterior to the rostral process, the rostrum is not compressed and does not expand evenly towards the jaw articulations as in most pterosaurs. In dorsal and ventral views, the jaw margins can be seen to rapidly increase in width to the second alveolus forming an approximate $70^{\circ}$ angle with their anterior end (Fig. 3D). This is the extent of the preservation on the right side of the tip of the rostrum, but on the left side this expansion is immediately followed by a concave lateral jaw margin 




FIGURE 3. Photograph and drawing of the rostral region of Sericipterus wucaiwanensis, gen. et sp. nov. (IVPP V14725). A, left rostral fragment in lateral view; B, left rostral fragment in medial view; $\mathbf{C}$, right maxillary fragment in medial view; $\mathbf{D}$, tip of rostrum of left rostral fragment in ventral view. Abbreviations: aj, ascending process of the jugal; aof, antorbital fenestra; j, jugal; jm, jugal process of maxilla; $\mathbf{l}$, left alveolus; $\mathbf{L}$, left tooth; mj, maxillary process of the jugal; $\mathbf{m m}$, medial process of the maxilla; $\mathbf{n}$, external naris; $\mathbf{n f}$, medial flange on nasal process of the maxilla; $\mathbf{n m}$, nasal process of the maxilla; $\mathbf{o j}$, lower orbital bar on the jugal; pb, premaxillary bar; r, right alveolus; rr, rugose ridge; $\mathbf{R}$, right tooth; rc, rostral crest; X.l, left element; X.r, right element. Scale equals $5 \mathrm{~cm}$.
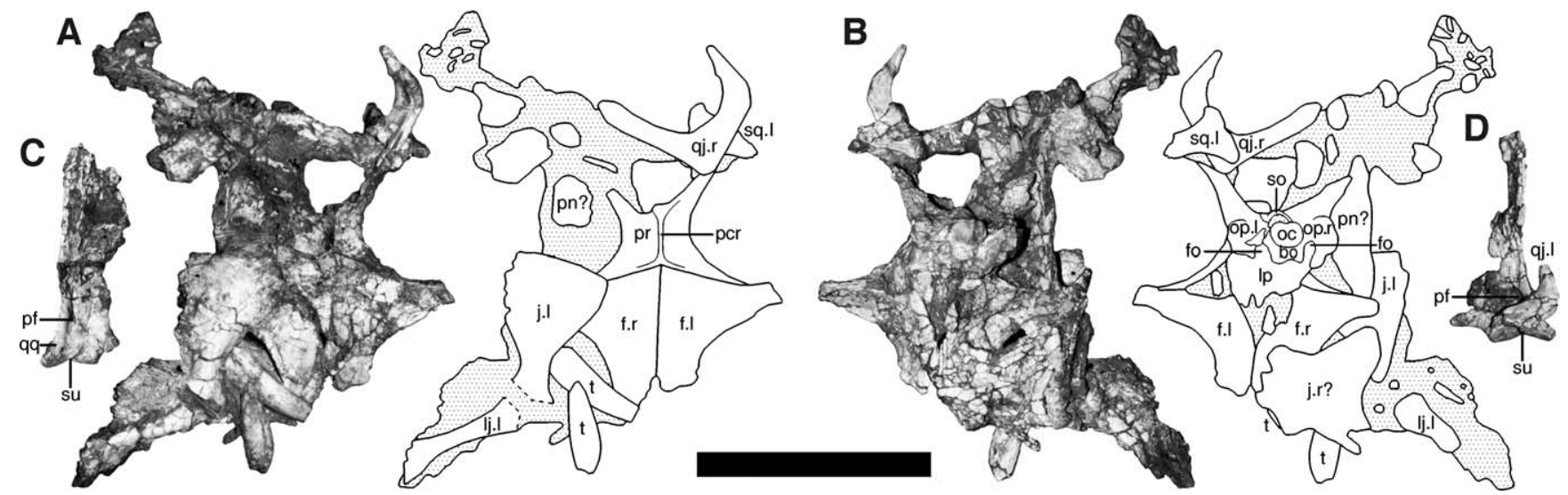

FIGURE 4. Photograph and line drawing of the temporal and occipital regions of Sericipterus wucaiwanensis, gen. et sp. nov. (IVPP V14725), in A, dorsal; $\mathbf{B}$, ventral view; and photographs of the $\mathbf{C}$, right; $\mathbf{D}$, left quadrate in anterior view. Abbreviations: aj, ascending process of the jugal; $\mathbf{f}$, frontal; $\mathbf{f o}$; foramen; $\mathbf{j}$, jugal; lp, laterosphenoid and prootic region; oc, occipital condyle; op, opisthotic; pcr, parietal crest; pf, pneumatic foramen; pn, palatine; pr, fused parietals; qj; quadratojugal; qq, articular facet for quadratojugal on the quadrate; so, supraoccipital; sq, squamosal; su, sulcus; t, tooth; X.I, left element; X.r, right element. Stippled regions represent matrix or matrix covered bone. Dashed lines represent the break between the left jugal and the ascending and maxilla processes of the jugal. Scale equals $5 \mathrm{~cm}$. 

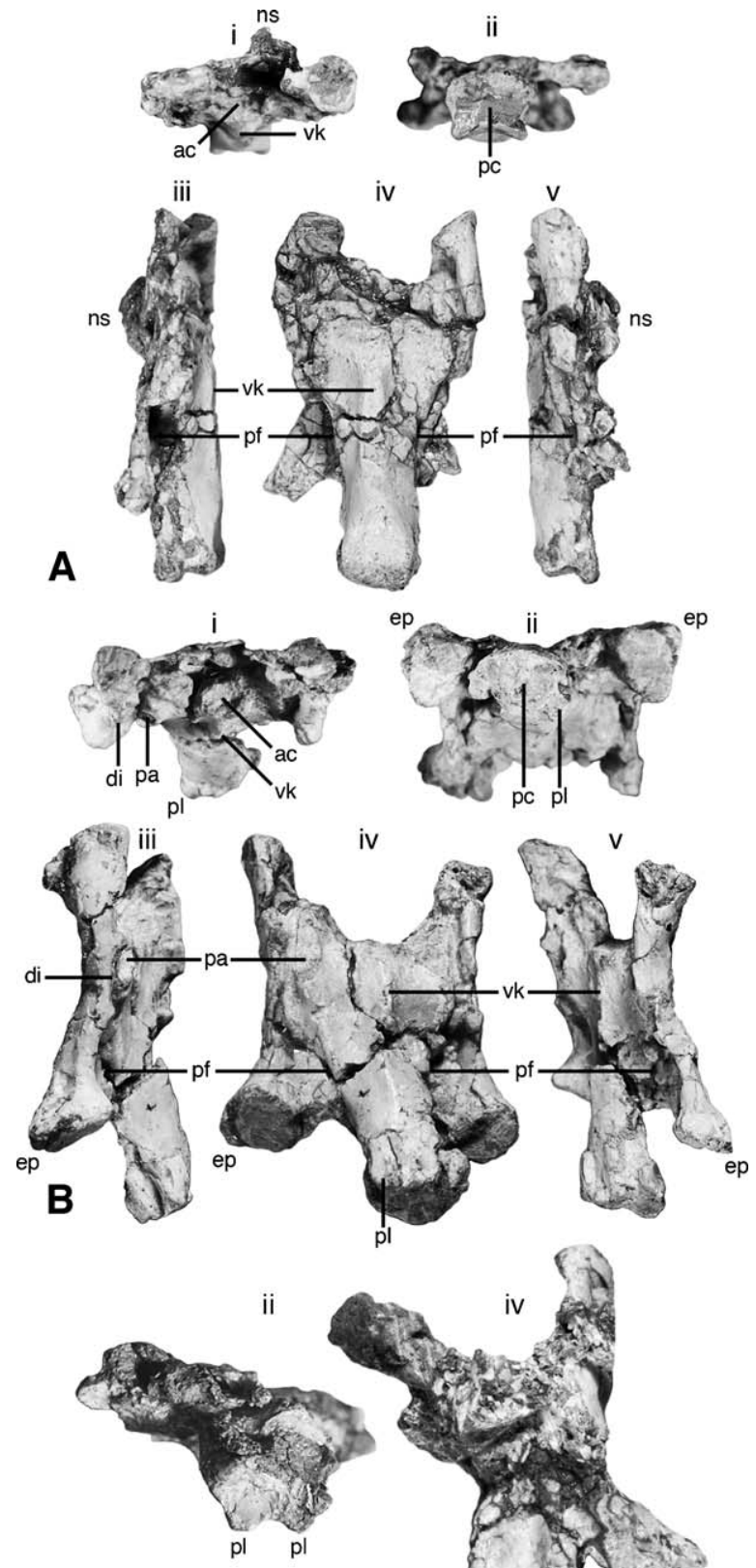

C

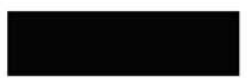

iv
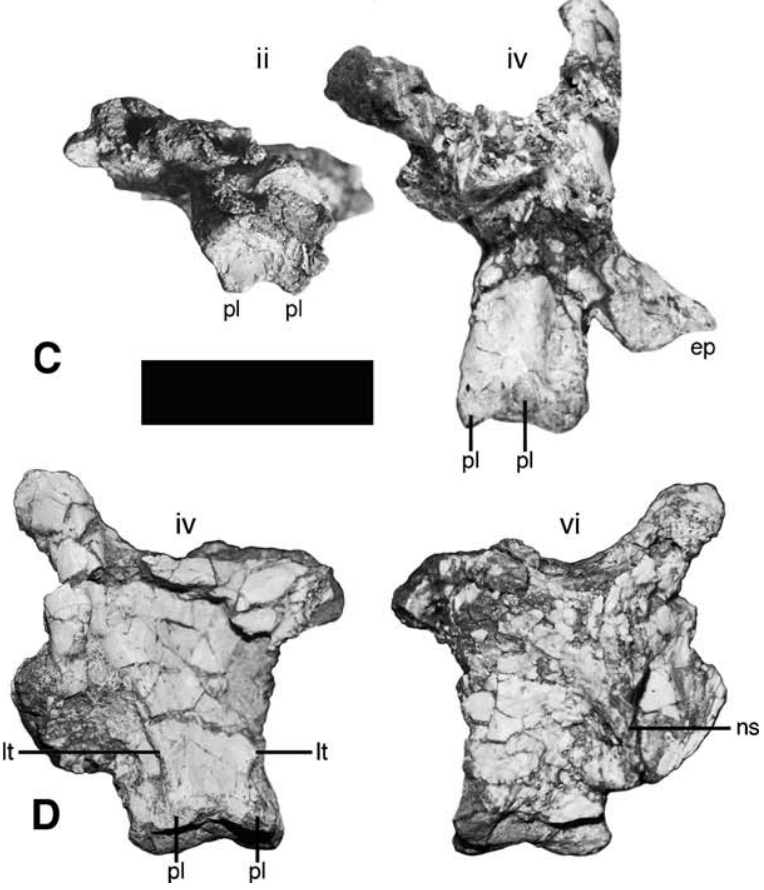

FIGURE 5. Photographs of the cervical vertebrae in Sericipterus wucaiwanensis, gen. et sp. nov. (IVPP V14725). A, cervical 3; B, cervical 5; C, cervical 7; D, cervical 8; in i, anterior; ii, posterior; iii, right lateral; iv, ventral; $\mathbf{v}$, left lateral; and vi, dorsal view. Abbreviations: ac, anterior cotyle; di, diapophysis; ep, epipophysis; It, lateral tubercle; ns, neural spine; pa, parapophysis; pc, posterior condyle; pf, pneumatic foramen; pl; postlateral projection of centrum; vk, ventral keel of centrum. Scale equals $2 \mathrm{~cm}$. denoting a constriction in the skull posterior to an expanded tip of the rostrum.

It is difficult to discern the width of the skull posterior to the rostrum. The less crushed right maxilla is mediolaterally broad and has its nasal process dorsomedially oriented, indicating that the skull was rather broad at this region. All of the teeth preserved in the specimen curve along an axis perpendicular to the long axis of their cross-sections with the exception of the first tooth-pair. The alveoli and in situ teeth in the jaw margins indicate that this long axis is the mesiodistal axis as in other pterosaurs. To accommodate the occlusion of this lingually curving dentition, the jaw margins would have to incorporate some lateral orientation. Therefore, the teeth must have been directed laterally to some degree but the exact angle is not known. The alveoli project from the jaw margin, tracing a sinuous outline. The premaxillae and maxillae apparently do not contribute to the palate.

While being prepared, the premaxillary bar of IVPP V14725 was shifted slightly dorsally, giving the skull the higher posterior outline seen in Figure 3. The premaxillary bar is fragmented and may represent the disassociation of the left and right premaxillae from one another in this region. The anterior part of the external naris is preserved in both halves of the rostra. It is a remarkably elongate, anteriorly inclined, and narrow opening. Its dorsal and ventral margins are nearly straight and parallel to one another. The rounded anterior- and ventral-most margin of the naris lies well above the ventral margin of the antorbital fenestra. The antorbital fenestra is a much deeper opening with a larger, more rounded anterior margin.

The contact between the premaxillae and maxillae is not visible in medial or lateral view and they are likely fused. On both halves of the rostrum, the nasal process of the maxilla is nearly straight and inclined about $30^{\circ}$ from the horizontal. This process is T-shaped in cross-section due to a flange extending along the medial aspect of this process (Fig. 3). The contact surface on the left maxilla for the jugal is preserved, indicating these bones were not fused. At this contact, the maxillary process of the jugal is directed anterodorsally to extend over the jugal process of the maxilla (removed in Figure 3). The contact surface on the maxilla curves anteromedially to reach the anterior margin of the antorbital fenestra on its medial aspect.

On the medial aspect of both maxillae, a flat shelf of bone extends posteroventrally from the anterior end of the antorbital fenestra orthogonal to the surface of the maxilla proper. This can be seen best on the right maxilla (Fig. 3C), whereas on the left half it remains as a broken process near the base of the nasal process of the maxilla and has been shifted laterally into the antorbital fenestra. This shelf contacts the medial flange on the nasal process forming an internal fossa, presumably housing a paranasal diverticulum (Witmer, 1997), at the anterior margin of the antorbital fenestra. A rugose ridge extends anteriorly under the external naris from this point. This shelf tapers posterolaterally and somewhat resembles pterosaur palatines in this manner. However, this would imply both a more dorsal position and greater inclination for the palatines than is seen in other pterosaurs. In addition, these elements do not seem to be separate bones from the maxillae. These shelves are termed the medial processes of the maxilla. They may be the original maxillary contributions to the palate but have subsequently been displaced dorsally due to the posterior expansion of the palatines, diagnostic for pterosaurs (Romer, 1956).

The midsection of the right jugal was found lying under the left rostral fragment and was left attached to its medial surface during preparation (Fig. 3A-B). The maxillary process, ascending process, and the lower bar of the orbit are present, but incomplete. These processes are perpendicular to one another. In addition, the jugal proper is missing a piece of its ventral margin at the junction of these processes and interrupting an otherwise straight ventral margin in this region. On the lower orbital bar of the jugal, a crescentic articular facet curves anteroventrally along the 



FIGURE 6. Photographs of the appendicular elements of Sericipterus wucaiwanensis, gen. et sp. nov. (IVPP V14725). A, right scapulocoracoid in lateral view; $\mathbf{B}$, proximal end of right radius in anterior view; $\mathbf{C}$, proximal end of right ulna in anterior view; $\mathbf{D}$, distal end of left ulna in anterior view; right humerus in $\mathbf{E}$, ventral, $\mathbf{F}$, dorsal, and $\mathbf{G}$, proximal view; $\mathbf{H}$, left first wing phalanx in dorsal view without extensor tendon process; $\mathbf{I}$, right second wing phalanx in dorsal view; $\mathbf{J}$, distal end of left third wing phalanx in dorsal view; $\mathbf{K}$, proximal end of right third wing phalanx in dorsal view; $\mathbf{L}$, proximal end of left fourth wing phalanx in dorsal view; $\mathbf{M}$, right fourth wing phalanx in dorsal view; and metatarsal A in $\mathbf{N}$, lateral, $\mathbf{O}$, dorsal $\mathbf{P}$, proximal, and Q, distal view. Abbreviations: ap, acrocoracoid process; co, coracoid; dc, dorsal condyle; dco, dorsal cotyle; dp, deltopectoral crest; ect, ectepicondyle; gf, glenoid fossa; gr, groove; hh, humeral head; ms, muscle scar; nf, nutrient foramen; pf, pneumatic foramen; ppr, posterior process; sa, sternal articulation; sc, scapula; tub, tubercle; uc, ulnar crest; vco, ventral cotyle. Scale equals $5 \mathrm{~cm}$.

posterior aspect of a short dorsal process and onto the medial aspect of the jugal. The lateral margin of this short dorsal process is not confluent with the lateral margin of the jugal proper, which is damaged and likely constituted part of the posterior expansion of the jugal. If so, the short dorsal process would be part of the anterior margin of the posterior expansion. The medial facet likely is the contact for the pterygoid or ectopterygoid and would indicate that the maxilla did not extend this far posteriorly along the medial side of the jugal. A similar condition has been reported in Pteranodon where a small dorsal process lies just anterior to the ectopterygoid contact with the jugal (Bennett, 2001a).

An isolated bone lying between the two halves of the rostra is identified as the right nasal (Fig. 2). It is an elongate, wedgeshaped bone with long and short edges separated by the margin of an oval fenestra on one end. These edges have a slight sinusoidal outline. If this identification is valid, then the long edge would correspond to the contact between the left and right nasals, and the free margin would correspond to the posterior margin of the right external naris. The overall shape of this bone also resembles the palatine of pterosaurs. However, the palatine contacts a fenestrae, the internal naris, posteriorly and not on one of the convergent edges as in this bone.

Among non-pterodactyloid pterosaurs, a midline process at the anterior tip of the rostrum can only be seen as present in Rhamphorhynchus, Angustinaripterus, and Harpactognathus. These processes are elliptical in cross-section in Sericipterus and Angustinaripterus, but triangular in Rhamphorhynchus and Harpactognathus. In Sericipterus, Angustinaripterus, and Harpactognathus, this rostral process is laterally compressed and connects posteriorly to a low premaxillary sagittal crest, collectively labeled a rostral crest in Figure 3. The posterior extent of the sagittal crest is not preserved in any of these pterosaurs. Premaxillary sagittal crests are widespread among pterodactyloids. They are also reported in the non-pterodactyloids Austriadactylus cristatus (Dalla Vecchia et al., 2002) and Raeticodactylus filisurensis (Stecher, 2008), but these crests are much higher and have a straight anterior margin in these species. Rostral expansions are reported here in Sericipterus and the other nonpterodactyloids, Angustinaripterus and Harpactognathus. Rostral expansions are present in some ctenochasmatid (Unwin, 2002) and in the anhanguerid pterodactyloids (Campos and Kellner, 1985; Bakhurina and Unwin, 1995; Unwin, 2003a). The rostral expansions in the non-pterodactyloids differ in their relative size; Sericipterus incorporates two pairs of teeth, Angustinaripterus has three pairs, and Harpactognathus has four pairs of teeth in its expansion. These three pterosaurs also share a sinuous dental margin, formerly listed as a diagnostic character of Harpactognathus by Carpenter et al. (2003). Sericipterus and the other rhamphorhynchines (sensu Unwin, 2003a) have elongate, parallel-sided external nares. Other non-pterodactyloids have more triangular external nares that, even when elongate and anteriorly inclined, maintain a flat base and a concave ventral margin. An antorbital fenestra with a ventral margin situated below 
the external nares is present in all rhamphorhynchids identified in the current phylogenetic analysis.

The condition of a T-shaped cross-section for the nasal process of the maxilla cannot be assessed in many pterosaurs. However, disarticulated maxillae in Campylognathoides, Dorygnathus, and Dimorphodon; fortuitous breaks in Harpactognathus and Angustinaripterus; and CT radiology of Rhamphorhynchus $(\mathrm{CMNH}$ 11434 ) indicate that it is absent in these taxa (B. Andres, pers. observ.) and therefore an apomorphic condition for Sericipterus. Harpactognathus has a similar but distinct condition in that the nasal process of its maxilla is dorsally thickened. A similar situation occurs with assessing the condition of the contact between jugal and the maxilla. A jugal that spirals around the maxilla to reach the medial aspect of the jaw margin as in Sericipterus can be observed in some pterodactyloid species (e.g., Dsungaripterus weii) (B. Andres, pers. observ.)). However, the distribution of this feature among the non-pterodactyloids is not known because the three-dimensional preservation required to assess this morphology is rare among these taxa. Shelf-like palatal processes on the maxilla can be seen in Angustinaripterus, but further distribution of this feature is not known.

Braincase and Temporal Region-The posterior region of the skull of IVPP V 14725 was preserved lying on its dorsal surface under the mandibles and right coracoid (Fig. 2). The braincase, frontals, fused parietals, portions of the left jugal, left squamosal, right quadrate, right quadratojugal, and possibly one of the palatines are present (Fig. 4). This region has been greatly fractured and crushed dorsoventrally so that identification of the other fragments and their margins is not possible, but these presumably belong to the missing palatal and temporal bones. In general, the cranium fractured through the supraoccipital with the other bones of the occiput rotated forward and the ventral braincase being dorsally displaced into the portion of the cranial cavity formed by the frontals. This left a small dorsal portion of the supraoccipital and parietals extending further backwards than the rotated occiput, visible as a small, rectangular flange in Figure 4.

The identifiable elements of the chondrocranium are largely limited to the bones of the occiput. In ventral view, the braincase narrows anteriorly from the occiput to where it is obscured by the frontals. The prootics and laterosphenoids presumably occupy this region and would include some of the fragments in this area, but their margins are not discernable. The occipital condyle is semicircular in cross-section with a slight neck and is apparently comprised only of the basioccipital. A slight groove extends along the otherwise flat dorsal flat margin of the condyle. A small piece of the right half of the condyle has become displaced slightly along a crack that extends through the region. Short lateral flanges attach to the sides of the condylar neck. Similar structures were identified as the exoccipitals in Rhamphorhynchus by Wellnhofer (1975). The left example of these two flanges has been detached and rotated, but no sutures are visible on either side to confirm that these are separate bones. The basioccipital is broken off ventrally at an apparent constriction in this bone leaving no trace of the basisphenoid. The ventral preserved end of the basioccipital is flanked laterally by two foramina, the 'foramen ovale' of Wellnhofer (1975) (Fig. 4B). However, these openings do not correspond to the fifth nerve opening between the prootics and laterosphenoids that is termed the foramen ovale in other taxa. They may be comparable to the subcondylar recess of theropods such as tyrannosaurids (Witmer, 1997). The opisthotics form large plate-like structures with round lateral margins and are missing their squamosal contacts. The left paroccipital process is more complete, extending out beneath the posterolateral process of the parietal to the region of the squamosal contact. The opisthotics contact the parietals dorsally and wrap around the 'foramen ovale' ventrally. The foramen magnum is relatively small and semicircular. It has a thickened dorsal rim formed laterally by the opisthotics and dorsally by the supraoccipital. The supraoccipital is rather small and has a low midline ridge.

The preserved skull roof in this region includes the frontals and parietals (Fig. 4A). The frontals and parietals are unfused to each other and are oriented coplanar to one another. The large frontals dominate this region of the skull and are complete save for the missing tips of their anterior and postorbital processes. A midline dorsal notch in the anterior margin of the frontals is presumably the contact for the premaxillary. The nasals do not extend posteriorly as processes in pterosaurs. The frontals contact the parietals along a broad, posteriorly convex transverse crest. The frontals have a nearly flat dorsal surface that extends laterally behind the large orbits as wide postorbital processes. In ventral view, the cristae cranii are broad and have ventrolaterally facing surfaces.

The fused parietals are much smaller relative to the frontals but still meet along the midline of the skull to exclude the frontals from contacting the supraoccipital, unlike the reconstruction of Rhamphorhynchus by Wellnhofer (1975). The parietals are dorsally arched above the braincase forming laterally sloping sides for the medial walls of the supratemporal fenestrae between the lateral and posterior processes of the parietal. A sizable distance between the posterolateral end of the parietal and the postorbital process of the frontal indicates that the supratemporal fenestra was large. A lateral process of the parietal abuts the postorbital processes of the frontals posteriorly, but is shorter and terminates before it would contact the postorbitals. The fused parietals bear a low, narrow sagittal crest. However, this crest does not extend above the dorsal margin of the skull and is therefore not equivalent to the parietal crests present in some pterodactyloid peterosaurs. This crest contacts the similar transverse crest that extends along the frontoparietal contact. The posterior processes of the parietals are tapered and oriented posterolaterally to where they would contact the squamosals.

A bell-shaped bone lying next to the left squamosal process of the parietal is identified as the left squamosal (Figure 4). Its overall form is of a broken process with two concave margins terminating in large, convex, laterally curving end. The only other bone in the skull with a similar shape would be the postorbital, which is more triradiate and has much narrower processes. If it is the squamosal, the broken process would correspond to the postorbital process, and the two concave margins as the ventral and dorsal margins of the infratemporal and supratemporal fenestrae, respectively. Because the more concave margin would correspond to the infratemporal fenestra and this bone curves slightly laterally, this element can be identified as the left squamosal.

An adjacent element is identified as the right quadratojugal. It is a rather large, U-shaped bone with tall anterior and posterior ascending processes. These processes would broadly contact the jugal and the quadrate. This bone traces the ventral margin of the infratemporal fenestra, which would therefore be rather large and have a round ventral margin. A raised edge traces the medial margin of the ventral and posterior margins of this bone. The anterior of the two ascending processes is straighter and about twice the length of the more posterior process. The lateral edge of this anterior process has been quite damaged. The more posterior process forms a sharp, hooked end that matches exactly a distinct anteriorly oriented facet on the lateral margin of the quadrate (Fig. 4C). The hooked process is all that remains of the left quadratojugal, which was found lying on top of the left quadrate and underneath the right maxilla (Fig. 4D). On the medial surface of the anterior end of the ventral margin is a narrow groove that may have articulated with a slender process of the jugal. The quadratojugal would have a broad contact with the ventral margin of the skull and exclude the jugal from contacting the quadrate. The inclination of the posterior 
hooked process indicates that the quadrate was relatively inclined with respect to the ventral margin of the rostrum.

Lying between the anterior and posterior processes of the right parietal is an elongate bone that is visible in dorsal and ventral views of the braincase. Though poorly preserved, its elongate, triangular outline and large size suggest that this is one of the palatines.

On the dorsal aspect of the skull is an incomplete bone with a greatly expanded end, a middle constriction, and a straight process that has been broken off at its base but connects at a right angle to the long axis of the rest of the bone. This bone is identified as the left jugal. The expanded end corresponds to the posterior margin that would contact the anterior ascending process of the quadratojugal. A process would have extended dorsally from this posterior margin to contact the postorbital, but this has been broken off at its base. The middle constriction corresponds to the ventral-most margin of the orbit, and the elongate, broken process would be the ascending process of the jugal. The exact orientation of the ascending process cannot be determined. The broken base of the maxillary process is evident just ventral to the ascending process. The ascending process of the left jugal preserves part of its dorsal-most expansion and possibly includes portions of the lacrimal and/or prefrontal. This expansion would lie near the skull roof so that taking the entire height of the preserved jugal provides a minimum skull height estimate at the front of the orbit of $51.5 \mathrm{~mm}$. The posterior end of the jugal is expanded ventrally. This ventral expansion is likely the posterior process of the jugal found in other pterosaurs but oriented vertically in this specimen. A large flat bone with two divergent processes lying on the ventral aspect of the frontals is likely the posterior end of the right jugal. This element is highly fractured and its identification is not certain.

The right quadrate was found in contact with the right quadratojugal, and the left quadrate was found underneath the right rostral fragment in contact with the posterior end of the left quadratojugal (Fig. 2, but removed in Fig. 3A-B). Both quadrates are missing their dorsal ends but are otherwise well preserved (Fig. 4C-D). The quadrates are anteroposteriorly compressed and would have had very little exposure on the lateral surface of the skull. This exposure is limited to the laterally offset lateral condyle of the jaw articulation and the thin flange extending dorsally from its posterior margin. The flange forms an anteriorly oriented vertical groove to receive the posterior margin of the quadratojugal. This facet is wider near its base, giving it an overall squat, subtriangular shape. The rest of the lateral surface is straight and recessed from what would be the lateral margin of the skull. The quadrates have well-developed obliquely aligned, double condyles. The lateral condyle is well offset laterally to the extent that the margins of the condyles do not overlap in anterior or posterior view. This is in contrast to the relative elongate shape of the condyles, whose long axis is more than three times the length of the short axis. The condyles and the strong sulcus that divides them are oriented $45^{\circ}$ anteromedially from the sagittal plane. A small, presumably pneumatic, foramen dives dorsally into the anterior aspect of the quadrate just lateral to the quadrate midline and level with the dorsal termination of the quadratojugal articulation. A sharp, anteromedially curving process extends from the medial side of the left quadrate's ventral end. This process would presumably contact the pterygoid. The quadrates are laterally thicker in cross-section. On the right quadrate fragment, the lateral thickening shifts slightly medially near the dorsal end so that the lateral edge becomes a flange dorsally. The medial margin is poorly preserved in both quadrates, but can be seen to expand medially in the right quadrate to where it would eventually contact the occiput.

The posterior aspect of the skull in non-pterodactyloids is effectively described from a single specimen of Rhamphorhynchus (CMNH 11434, see Wellnhofer, 1975; http://www.digimorph.
org/specimens/Rhamphorhynchus_muensteri/). The occipital region of IVPP V 14725 largely agrees with Wellnhofer's (1975) reconstruction of Rhamphorhynchus, with the exception of a much smaller supraoccipital and conversely larger parietals. The supraoccipital therefore does not contact the frontals as reconstructed by Wellnhofer (1975). The parietals have a significant contact with the postorbital processes of the frontal, but are still dwarfed by the frontals. Large, V-shaped quadratojugals are reported in Dorygnathus (Padian and Wild, 2008) and reconstructed in Parapsicephalus purdoni (Newton, 1888), but these are much shorter anteroposteriorly and do not have a broad contact with the ventral margin of the skull. Sericipterus, however, has longer, U-shaped quadratojugals that are as long as they are tall, unlike the shorter quadratojugals in these other taxa. Inclined quadrates are present in all but the basal-most pterosaurs (Unwin, 2003b). Quadrates with oblique condyles separated by a posterolaterally oriented groove for articulation with the mandible have been coded in some pterodactyloids such as Quetzalcoatlus (Kellner and Langston, 1996) and termed helical jaw joints (Eaton, 1910). They are also present in Sericipterus, Dorygnathus, and Rhamphorhynchus. They cannot be observed in Cacibupteryx and Angustinaripterus. An expanded posterior end with a ventral process on the jugal is also present in Angustinaripterus. The midline sagittal crest on the parietals has not been reported in non-pterodactyloids and is most similar to the blunt sagittal crest coded in the anhanguerids (Kellner, 2003). A ridge at the contact between the frontals and the parietals has been reported in the pterodactyloid Gegepterus changi (Wang et al., 2007).

Mandible - The right and left mandibular rami are present though severely cracked and distorted (Fig. 2). The right ramus is more complete but is twisted along its length and missing the anterior end. This ramus is relatively straight, dorsoventrally low, laterally compressed, and tapers slightly anteriorly. The remains of two crushed alveoli are visible anteriorly in the right ramus, but it is not known how many more teeth or how much more of the mandible is missing. The left ramus is very poorly preserved and comprises only the posterior end of the ramus. The adductor fossa, the cranial articulation, and a detached surangular are the only features that can be recognized on this element. The adductor fossae, best preserved on the right, are elongate, narrow, and elliptical in shape. The right fossa is about $53 \mathrm{~mm}$ long and reaches nearly the entire length of the surangular to terminate just anterior to the cranial articulation. The surangular is an elongate, thin bone positioned along the dorsal edge of the posterior third of the preserved ramus. There is no distinct coronoid process. The prearticular extends from the cranial articulation along the medial aspect of the ramus and ventral to the fossa. The contact between the articular and splenial is not discernable, but the splenial can be seen to extend anteriorly from the fossa to terminate as a sharp wedge about halfway down the preserved length of the mandible. The margins of the articular, angular, and posterior terminus of the dentary are not visible. The cranial articulation, best preserved on the left, is gently concave dorsally and nearly square in outline. The anterior edge of the articulation surface comprises robust medial and lateral processes separated by a depression. The medial process is the larger of the two, nearly twice as broad as the lateral process, and about equal in breadth to the depression between them. These processes form the anterior margins of the posterolaterally facing medial and lateral articular facets. A very slight posterior buttress is present but is far enough posterior that some anteroposterior movement of the mandible may have been possible. A short, blunt, and triangular retroarticular process is present.

Dentition-Eighteen tooth fragments that could at minimum represent 12 teeth are preserved around the two skull regions. They have smooth, glossy enamel that is stained blue in some 
fragments. Most of the preserved teeth are isolated and consist only of portions of the crowns. The right second and the left third teeth remain in their alveoli, but the left third tooth is broken off at its base. A tooth found lying on the right aspect of the left rostral fragment next to the right tooth is identified as the right third tooth based on its similar position, size, and cross-section as the left third tooth, which was found in the largest rostral alveolus (Fig. 3A-B). The largest isolated tooth in IVPP V 14725 is of similar size and was found next to the proximal right ulna and radius (Fig. 2). The rostral alveoli increase in size to the third alveolus and then decrease in size distally. A tooth closely associated with the tip of the rostrum (Fig. 2) is relatively less compressed and similar in cross-sectional size to the first alveoli pair and is most likely the left or right first tooth. The largest isolated tooth is likely the largest tooth from the mandible and from a similar position in the tooth row.

Alveolar spacing increases distally along the rostrum with the distance between successive teeth always exceeding the diameters in respective teeth. It is not known how far back in the skull the tooth row extended. The tooth rows begin about three $\mathrm{mm}$ behind the preserved tip of the rostral process where they lie very close to the midline of the skull. The left half of the rostrum preserves the mesial-most three alveoli, but the poorly preserved outline of a fourth alveolus is likely present in the sinuous outline of the jaw margin. An alveolus in a similar position on the right maxillary fragment and second alveolus distal to it would bring the tooth count along each side of the rostrum to at least five. If the tooth row terminated under the antorbital fenestra as in other Jurassic non-pterodactyloids, the tooth row could contain up to seven teeth bringing the rostral tooth count to anywhere between 10 and 14, and the total tooth count to between 20 and 28 teeth assuming a similar number of teeth present in the mandible. The rostral tooth row extends past the anterior margin of the external naris, or at least $40 \%$ of the minimum estimated skull length.

The rostral tooth row has raised borders on the mesial and distal edges of each alveolus giving the jaw margin a sinuous outline. All alveoli are labiolingually compressed but are less compressed mesially. The putative first tooth is the least recurved tooth in the specimen, suggesting that the rostral teeth increase in curvature to the third tooth. All other teeth are curved. The anteriormost alveoli are inclined anteriorly about $30^{\circ}$ from the horizontal plane, the left second about $45^{\circ}$, the left third about $75^{\circ}$, and right fourth and fifth are subvertical.

The teeth are elongate, labiolingually compressed, and terminate in sharp tips. Tooth lengths range from 24 to $53 \mathrm{~mm}$, of which half is erupted height. Short, isolated teeth are present so it is most probable that the teeth decreased in height as well in diameter distal to the third tooth. With the possible exception of the mesial-most teeth, the teeth curve strongly lingually over their entire erupted height at right angles to their mesiodistal long axis. The roots are essentially straight and end in a small, circular nutrient foramen. The possible right third tooth has the largest curvature in IVPP V14725. Its 10.4-mm ventral displacement along its curvature indicates that the tip would have extended well ventral to its alveolus. The mesial rostral teeth are partially laterally oriented, but it is most probable that all of the dentition had some degree of lateral orientation to accommodate their curvature. The mesial and distal edges of the teeth have thin, sharp enamel keels extending along the length of the erupted tooth to the tip. The distal keel is distinctly sharper, forming a long cutting surface.

Compared to the 10-14 rostral teeth of Sericipterus, Angustinaripterus has 18 (He et al., 1983), Harpactognathus has at least 12 (Carpenter et al., 2003), Rhamphorhynchus has 17, Dorygnathus has 22, and Scaphognathus has 14 (Wellnhofer, 1978). All non-pterodactyloids except for the anurognathids and Sordes pilosus have labiolingually compressed teeth. In Sericipterus, all of the dentition is labiolingually compressed, whereas the other rhamphorhynchids have teeth circular in cross-section at the mesial end of their dentitions. Slender teeth are present in all the rhamphorhynchids, which become more elongate in the rhamphorhynchines. Procumbent and strongly curved teeth are present in all rhamphorhynchines, but it is only in Rhamphorhynchus that the entire dentition is procumbent. The mesial and distal enamel keels with a sharper distal ridge, as in the teeth of Sericipterus, have been reported in Rhamphorhynchus (Wellnhofer, 1975) and seem to be to be present in Angustinaripterus. In Sericipterus and Angustinaripterus, the teeth are directed to some degree laterally and curve lingually, whereas the teeth of the other rhamphorhynchids are upright and recurve posteriorly. This lingual curvature of the teeth is perpendicular to the direction of curvature from the rest of the non-pterodactyloids. The cross-sectional long axes of the mesial-most teeth are not parallel to the sagittal plane in Sericipterus. The similar position of the mesial and distal enamel keels and mesiodistal long axis of the teeth confirm that this is a novel direction of curvature as opposed to the rotation of the teeth within their alveoli with respect to other pterosaurs. Harpactognathus has laterally directed alveoli, but because no teeth were found with the only known specimen, it is not known if it shares a lingually curving, keeled dentition.

\section{Axial Skeleton}

Remains of six cervical, nine dorsal, and at least two sacral vertebra are preserved in the axial skeleton in IVPP V14725 (Figs. 2 and 5, Table 2). The six cervical vertebrae are very similar in morphology and so represent cervicals 3 to 8 , the longest series of similarly shaped vertebrae within the cervical series. Cervical 8 is obscured and not shown in Figure 2. The dorsal vertebrae can be recognized as the posterior end of the dorsal series because of their contact with the pelvis. They are identified as dorsals 6 through 14. If the first vertebra that bears a large rib that articulates with the sternum is identified as the first dorsal vertebra as suggested by Bennett (2007), then non-pterodactyloid pterosaurs typically have 13 to 15 dorsal vertebrae (modified from Romer, 1956). Specimens of Anurognathus ammoni have, however, been reported with as few as 11 or 12 dorsal vertebrae (Bennett, 2007). The successive closest relatives to Sericipterus, Rhamphorhynchus and Dorygnathus, have 14 (modified from Wellnhofer, 1975) and 13 (after Padian and Wild, 2008) reported dorsals, respectively. Because Rhamphorhynchus shares a closer relationship, its dorsal count was used to assign positional identity, but it is possible that the original identities could be off by up to two positions. The two sacrals are identified as sacrals 1 and 2 based on the unfused cotyle of the first sacral vertebrae and the orientation of their sacral ribs. All vertebrae with recognizable intervertebral articulations are procoelous. No sutures are visible on any of the vertebrae. A number of elongate elements, averaging about $2 \mathrm{~mm}$ in diameter, preserved adjacent to the humeri, are likely parts of dorsal ribs based on their size, position, and shape.

Cervical Vertebrae-The cervical vertebrae were found disarticulated and lying on their dorsal surfaces. These dorsal surfaces are very poorly preserved and so are not figured with the exception of cervical 8 (Fig. 5). The cervical vertebrae in this specimen have similar overall morphology but display variation along the series that, along with the relative size of the preserved elements, were used to assign their positional identity. Pterosaurs are interpreted as having nine cervicals (sensu Bennett, 2007): an atlas-axis complex, five middle-series cervicals, and two posterior-series cervicals. The two post-cervicals resemble the vertebrae of the dorsal series to varying degrees across pterosaur phylogeny. IVPP V 14725 preserves the mid-cervical series and the anterior of the two post-cervicals so that only the atlas-axis complex and cervical 9 are missing. Cervicals 3, 5, 7, and 
TABLE2. Measurements of the identified elements of the vertebral column of IVPP V14725 (in mm).

\begin{tabular}{lcc}
\hline Element & Centrum length & Mid-width \\
\hline Cervical 3 & 23.3 & 15.1 \\
Cervical 4 & 19.3 & 14.6 \\
Cervical 5 & 24.5 & 18.7 \\
Cervical 6 & $?$ & $>10.5$ \\
Cervical 7 & 17.1 & $?$ \\
Cervical 8 & 22.5 & 25.2 \\
Dorsal 5 & $>8.8$ & 7.4 \\
Dorsal 6 & 14.3 & 5.7 \\
Dorsal 7 & 14.6 & 6.1 \\
Dorsal 8 & 14.7 & 7.3 \\
Dorsal 9 & 14.3 & 6.2 \\
Dorsal 10 & 14.0 & 7.2 \\
Dorsal 11 & 12.7 & 7.5 \\
Dorsal 12 & $\sim 12.6$ & $\sim 7.0$ \\
Dorsal 13 & $\sim 12.6$ & $\sim 5.3$ \\
Sacral 1 & 8.5 & 16.9 \\
Sacral 2 & 8.2 & 17.8 \\
\hline
\end{tabular}

$?=$ cannot be measured $>$ = preserved length $; \sim=$ approximate.

8 are the best preserved and are illustrated in Figure 5. Cervicals 4 and 7 each consist of only the posterior condyle and portions of the neural arch. No cervical ribs can be identified. However, distinct rib facets present on the cervical vertebrae indicate their presence in the living organism. The size of the rib facets is suggestive of elongate cervical ribs being present, but this cannot be confirmed.

Cervical 3 differs from the other mid-cervical vertebrae in being relatively smaller and narrower (Fig. 5A). Though there is variation in length along the mid-cervical series, these vertebrae are subequal in length, ranging between 1.6 and 1.8 times the average length of preserved dorsal vertebra. Cervical 3 shares with the other mid-cervicals a lateral, transverse crest extending from the prezygapophyses to the postzygapophyses. A ventral lip extends along the lateral margin of the transverse crest at least anterior to the rib articulations. Posterior to the rib articulations the transverse crest and postzygapophyses are too poorly preserved to resolve their morphology. Anteriorly, the ventral lip of the transverse crest contacts the base of the prezygapophyseal articulation to form a small, deep fovea. In other vertebrae, this pit may be filled with matrix and resemble a foramen, but they are all identified as foveae here. The prezygapophyses bear expanded, subcircular, nearly flat articular surfaces oriented anteromedially at an angle about $45^{\circ}$ from horizontal. The dorsal aspect of cervical 3 is poorly preserved but the anterior end of the neural spine is preserved. The neural spine is a thin crest that reaches the anterior margin of the neural arch, but its height and posterior extent cannot be seen. The anterior margin of the dorsal laminae of the neural arch overhangs the anterior cotyle. The anterior margins of both the neural arch and centrum bound a triangular recess that houses a flat-bottomed neural canal. There are no traces of lateral or a medial pneumatic foramina flanking the neural canal. The anterior cotyle is a broad ellipse in anterior view, but in ventral view it is a deep, semicircular crescent. The anterolateral ends of the anterior cotyle form buttresses with the bases of the prezygapophyses and the lateral laminae of the neural arch. This is the position of the parapophysis that lies ventromedial to its sister diapophyses on the transverse crest at the base of the prezygapophysis. The left prezygapophysis is well preserved; it forms a broad anteromedially facing surface with only a slight upward tilt as preserved. A narrow sulcus separates the rib articulations, but no more of their shape can be resolved on this vertebra. The rib articulations are at the widest point of the centrum from which the centrum rapidly decreases in width to a near constant width over its posterior half, giving the entire cen- trum a T-shape in ventral view. The entire vertebra including the posterior condyle is straight. At its widest, the centrum laterally contacts the lateral neural arch, but posteriorly the lateral laminae of the neural arch are positioned dorsally. This posterior lateral surface is pierced by small, elliptical pneumatic foramina in the region just anterior to the base of the postzygapophysis, one on each side. These foramina lie in shallow lateral excavations of the neural arch. The right side of cervical 3 has been damaged in this region, making the foramina appear larger on this side. Just posterior to the anterior cotyle, a flat-bottomed ventral keel extends posteriorly along the midline of the centrum, giving the centrum an inverted triangle cross-section in this region. Posteriorly, this ridge terminates at the intersection with a posteroventrally oriented concave surface. This concave surface angles up to the posterior condyle to form a posterodorsally oriented, ventrally curved lip at its contact with the condyle. This lip is mirrored by another ventrally curved lip at the dorsal margin of the condyle so that the entire articular surface is an inverted crescent (Fig. 5A). The entire posterior condyle resembles the saddle-shaped heterocoelous articulation of birds. It differs from the avian condition, however, in that the articular surface curves ventrally instead of expanding at its lateral margins, and lacks a lateral lip, merging instead with the lateral surface of the centrum.

Cervical 4 is preserved only as the posterior condyle of the centrum and the lateral lamina of the left neural arch (Fig. 2). It bears a distinct, elliptical lateral pneumatic foramen on the neural arch in a similar position to that seen in the other mid-cervical vertebrae. It is identified based on similarities in its morphology to cervical 3 and the slightly larger size of the posterior condyle.

Cervical 5 is broadly similar to the previous cervicals, but larger and better preserved (Fig. 5B). It is the longest vertebra preserved in the specimen. The anterior margin of the neural arch does not overhang the anterior cotyle and the thin neural spine does not reach this anterior margin. Rib articulations are present and more visible than in cervical 3. The parapophysis is an elongate, concave, and semicircular articular surface. The diapophysis is similar in shape except that it is laterally thinner and forms a ventral emargination where is intersects the lip of the lateral transverse crest. The ventral lip of the transverse crest extends the entire distance from the prezygapophysis to the postzygapophysis. No middle constriction is apparent in the lateral margins of the transverse crests, the mid-sections of which are straight. The zygapophyses project from these straight lateral margins, with the postzygapophyses projecting more laterally than the prezygapophyses. The posterior condyle extends well posterior to the postzygapophyses as in the other cervical vertebrae. In cervical 5, the posterior condyle has been broken at its based and shifted ventrally. Originally, the posterior condyle would have pointed directly posteriorly as in the other cervicals. The zygpapophyseal articulations are slightly laterally compressed and more oval than on cervical 3. They are robust and inclined about $20^{\circ}$ from vertical, the prezygapophyses facing slightly dorsally and the postzygapophyses facing slightly ventrally. Distinct epipophyses are developed as processes that overhang the dorsolateral margins of the postzygapophyseal articular surfaces. A shallow groove extends around the base of the epipophyses. The ventral keel is much thinner than in cervical 3. A posteroventral concave surface again separates the ventral keel from the posterior condyle, but this surface does not form a continuous ventral lip with the condyle. The dorsal lip is present, but all that is present of the ventral lip is the right posterolateral extension of the articular surface that connects with a ventrolateral ridge extending along the lateral margin of the ventral concave surface. The left ventral part of the condyle is damaged, but these projections were presumably paired structures as in the succeeding vertebrae. The combined ridge and extension of the posterior condyle are termed here postlateral projections of the centrum. The lateral surfaces of the posterior condyle contact a 
lateral sulcus extending anterior along the centrum from the posterior condyle. The outline of the posterior condyle in ventral view is still convex.

Cervical 6 is identified on the basis of its relative size and is the most poorly preserved of the cervical vertebrae. It contains the eroded portions of the posterior condyle, right prezygapophysis and right postzygapophysis.

Cervical 7 is very poorly preserved with the exception of the posterior condyle (Fig. 5C). This cervical was found under cervical 3 and presumably crushed by the overlying vertebra (Fig. 2). No measurements could be taken on this vertebra. Besides the condyle, the two prezygapophyses, and the left postzygapophysis bearing a sharp epipophysis, can be recognized. The articular surface of the slender left prezygapophysis faces dorsomedially at an angle of about $45^{\circ}$, unlike the more vertical zygapophyses articulations in the preceeding cervicals. The posterior condyle is quite distinct from that of the preceding vertebrae. There is a depression immediately anterior to the posteroventral surface. The postlateral projections are more robust, extending both ventrally and posteriorly so that they would have contacted the succeeding vertebra both ventrally and anteriorly. Though distinct, the margins of these projections are confluent with their surrounding surfaces so that no grooves, sulci, or any other linear structures denote these as separate processes in any cervical. These projections give the condyle a biconvex shape in ventral and posterior view. Deep sulci extend along the lateral faces of the centrum from the condyle.

Cervical 8 is identified as a posterior-series cervical vertebra because it is wider than the centrum length and resembles a dorsal vertebra more than any other cervical (Fig. 5D). Its identification as the eighth in the cervical series is based upon the absence of small, closely situated prezygapophyses, the absence of thin transverse processes, and the absence of an anteroposteriorly short centrum, all of which are found in the typical nonpterodactyloid cervical 9 (B. Andres, pers. observ.). This vertebra was crushed obliquely so that the main portions of the neural arch were shifted laterally to the right. The left prezygapophysis has had its base broken off and shifted onto the ventral aspect of the centrum. The postzygapophyses are missing, but if the identification as cervical 8 is correct, they would extend directly posteriorly near the midline. A neural spine broken off at its base is visible on the dorsal surface of the vertebra. This spine becomes wider anteriorly. It is not known if this spine has a different shape from the other vertebrae. The anterior margin of the neural arch does not overhang the anterior cotyle. The large, widely spaced prezygapophyses dominate this vertebra as in the eighth cervical of other pterosaurs. The transverse crests extend posteriorly from the prezygapophyses at least as far as the mid-section of the vertebra, but it cannot be determined whether they contact the postzygapophyses. Rib facets in the same shape and position as in cervical 5 can be seen on the ventral surface and are separated by a narrow sulcus. No ventral ridge can be seen, though the anterior half of the ventral aspect of the centrum has been crushed. A posteroventrally oriented, concave surface cannot be seen on the posterior end of the centrum. Stout postlateral projections form the entire ventral lip of the posterior condyle giving the posterior margin a rounded, biconvex appearance. This is mirrored by more widely spaced projections of the dorsal lip of the condyle. Distinct sulci extend along the lateral surfaces of posterior centrum, halfway along which are lateral tubercles on the ventral surface of the centrum that may be attachment sites for collateral ligaments.

Overall, the cervical vertebrae of Sericipterus resemble larger and more robust versions of the cervicals of other nonpterodactyloid pterosaurs. Basal pterosaurs are typified by the presence of similarly shaped and sized centra throughout the mid-cervical series, distinct rib articulations, a square outline to the neural arch in dorsal view, and a centrum that is wider anteriorly. The rib articulations of Rhamphorhynchus are illustrated as a pair of sharp tubercles (Bonde and Christiansen, 2003; Wellnhofer, 1975:fig. 4b). In Sericipterus, however, the rib articulations are distinct, concave facets. It is possible that the sharp tubercles figured in Rhamphorhynchus are the broken off capitula and tubercula of the cervical ribs. Hypapophyses have been reported on the mid-cervical vertebrae of a specimen of Rhamphorhynchus (Geological Museum of Copenhagen 1891.738) (Bonde and Christiansen, 2003) at the position of the anterior termination of the ventral keel on the centra of Sericipterus. The hypapophyses of Rhamphorhynchus, however, are quite short and do not extend posteriorly. Pneumatic foramina in the lateral lamina of the neural arch are present in Rhamphorhynchus, Dorygnathus, and Sordes (B. Andres, pers. observ.). This last pterosaur has foramina piercing the arch near the base of the prezygapophysis instead of near the base of the postzygapophysis, and so it is possibly an independent development of cervical pneumaticity. In their description of the pneumaticity present in MGUH 1891.738, Bonde and Christiansen (2003) reported two additional pneumatic foramina on the lateral surface of the mid-cervical centra, but this has not been confirmed in other specimens.

Dorsal Vertebrae-Portions of nine dorsal vertebrae are preserved in IVPP V14725. The total number of original dorsals is not known and their identity is assigned on the basis of the dorsal vertebral count in Rhamphorhynchus. The preserved dorsal series is $107.7 \mathrm{~mm}$ long. Averaging the lengths of the preserved vertebrae and increasing to a total of 14 vertebrae would indicate an entire dorsal series approximately $168 \mathrm{~mm}$ long. Most of the dorsal vertebrae consist of preserved centra with varying amounts of their neural arches remaining. They are rather elongate and about twice as long as their widths or depths. Though subject to crushing and distortion, these vertebrae are subequal in length, varying less than two $\mathrm{mm}$ in length or width along the series.

The first vertebra in the series, identified as dorsal 6, consists of a posterior condyle with the neural arch missing, so that only the concave internal aspect of the neural canal is visible. The next dorsal is better preserved, though it has a large crack extending through its posterior end. This second vertebra has its neural arch preserved, but the transverse processes are broken off at their bases. The neural spine is a long, low, and thin crest. The original spine was most likely higher and has been broken off. The pre- and postzygapophyses are distinct, slim processes. The prezygapophyses are more slender, elongate, curving, and widely spaced than the postzygapophyses. There is a lateral fossa between the base of the transverse process and centrum proper but it cannot be seen to communicate with an internal space. The succeeding vertebra, identified as dorsal 8 , is the best preserved in the series. The neural spine reaches nearly the entire length of the neural canal. It has a slightly inclined appearance due to the convex and concave margins of the anterior and posterior margins of the spine, respectively. Again, the spine appears broken off above its base. The lateral lamina of the arch is rather short extending about half the length of the canal. The left transverse process is present and is the best preserved in the series. The rib parapophysis lies slightly anterior and medial in the same horizontal plane as the diapophyses but is not immediately anterior to the diapophysis. This morphology also corresponds to dorsal 8 in Rhamphorhynchus (Wellnhofer, 1975:fig. 6), assuming nine cervical vertebrae are present instead of eight (sensu Bennett, 2007). The fossa on the lateral lamina of the neural arch is the most distinct in the dorsal series and somewhat resembles a pneumatic foramen, but it does not communicate with an internal space. As can be seen in the following two vertebrae, which have had their neural arches sheared off at their lateral laminae, these laminae curve inward to create the lateral fossae as well as an hourglass shape for the neural canal in dorsal view. A break in the element identified as dorsal 10 appears to form a small hole in its right 
lateral margin, but this is not a natural hole. Posterior to these vertebrae, the preservation in the series degrades. The nominal dorsals 11 and 12 exhibit outlines of their centra, prezygapophyses, left transverse processes, and in the case of dorsal 12, the right transverse process and left postzygapophysis, but no further morphological details can be discerned. For the last two dorsal vertebrae, only the rough outline of centra can be traced. The intervening space before the sacrum also leaves space for only two dorsal vertebrae.

The dorsal vertebrae in Sericipterus are indistinguishable from those of other non-pterodactyloids that also have elongate centra (B. Andres, unpubl. data). Though this specimen lacks the pneumatic foramina reported in Rhamphorhynchus, pneumatic features are found in Rhamphorhynchus only anterior to dorsal 5 and are then only visible on the ventral surface of the transverse processes (Bonde and Christiansen, 2003). Therefore, it cannot be excluded that this specimen had pneumatic dorsals.

Sacrum and Pelvis-The pelvic region in IVPP V14725 is very poorly preserved and shifted to the left of the dorsal series (Fig. 2). The first two sacral vertebrae and one of the ischiopubic plates can be identified. The total number of sacral vertebrae is unknown. The sacral vertebrae are fused to one another and to their sacral ribs. Only the left sacral ribs are present and so the widths estimated in Table 2 are the result of doubling the distance from their lateral margins to the midline of the centra. The sacral ribs are short and flare laterally to enclose a single visible intertransverse foramen. The sacral rib of the first sacral is directed posterolaterally, whereas the following sacral rib is oriented straight laterally. The anterior cotyle of sacral 1 is visible and is a wide, dorsoventrally depressed oval. The rest of the sacrum is correspondingly depressed with a flat ventral surface. A thin, broken neural spine base is visible on the second sacral vertebra. The broad, fused ischiopubic plate of one half of the pelvis is present. Its surface texture is quite weathered, but its position suggests it is the right plate. If correct, then a thickened ridge extending away from the sacrum would correspond to the main body of the pubis. All pterosaurs have at least two sacrals, and broad, fused ischiopubic plates are present in all but the most basal pterosaurs (Unwin, 2003b).

\section{Pectoral Girdle}

In IVPP V14725, the right scapula and coracoid are all that remains of the pectoral girdle (Fig. 6A, Table 3). These elements generally fuse with one another during ontogeny (Bennett, 1993), but in this specimen they are unfused. A $30^{\circ}$ degree displacement between the long axes of the scapula and coracoid in the horizontal plane is most likely an artifact of preservation. The scapula and coracoid form about a $75^{\circ}$ angle with one another in a sagittal plane. The overall $\mathrm{V}$-shape of these elements is due to a $90^{\circ}$ flexure in the coracoid and a $30^{\circ}$ flexure in the scapula near their contact, as well as a slight $15^{\circ}$ curvature along the posterior ramus of the scapula. The glenoid fossa is oriented in the middle of the lateral surface of the scapulocoracoid. The posterior end of the scapula lacks an articulating facet for the vertebral column, precluding the possibility that the pectoral girdle had a laterally rotated anatomical position. The glenoid fossa is saddleshaped: concave in the transverse plane and convex in the horizontal plane.

The scapula is almost the same length as the rather elongate coracoid, but is more curved. Though the posterior ramus is damaged, it can be seen to be dorsoventrally depressed, have a nearly constant width, and lack an expansion at its posterior end. There is no distinct supraglenoid or medial buttress. Anterior to the scapular flexure, however, are medial and lateral tubercles that are likely the origins of the scapular head of the m. triceps as well as the confluent $\mathrm{m}$. subscapularis and $\mathrm{m}$. scapulohumeralis posterior, respectively (Bennett, 2003). Anterior to these tubercles, the
TABLE 3. Lengths of the appendicular elements of IVPP V14725 (in $\mathrm{mm})$.

\begin{tabular}{lcr}
\hline Element & Left & Right \\
\hline Scapula & - & 71.2 \\
Coracoid & $>80.1$ & 70.3 \\
Humerus & $>46.8$ & 100.2 \\
Ulna & $>20.0$ & $>45.8$ \\
Radius & 127.4 & - \\
First wing phalanx & -117.4 \\
Second wing phalanx & $>102.7$ & $>148.3$ \\
Third wing phalanx & \multicolumn{2}{c}{91.1} \\
Fourth wing phalanx & \multicolumn{2}{c}{$>77.9$} \\
Metatarsal A & \multicolumn{2}{c}{} \\
Metatarsal B
\end{tabular}

$-=$ missing element; $>=$ preserved length.

scapula expands to a subtriangular cross-section where it contacts the coracoid. The scapula constitutes about $60 \%$ of the glenoid fossa, and the dorsal lip of the glenoid fossa on the scapula is much larger than the ventral lip on the coracoid, extending onto the posterior margin of the scapula.

The coracoid has a right-angled flexure just ventral to the glenoid fossa. The posterior ramus is by contrast very straight and tapers in depth along its length. It is compressed side to side anteriorly, becoming dorsoventrally depressed posteriorly. Two marginal ridges trace this transition in shape down the shaft: one curving from the dorsal onto the lateral surface and the other curving from the ventral onto medial surface. These ridges are rugose along part of their lengths and are inferred to be the origins of the $\mathrm{m}$. costosternocoracoideus and $\mathrm{m}$. supracoracoideus, respectively. These ridges, and concomitant change in shape along the posterior ramus, give the coracoid shaft a twisted appearance. The lateral width of the coracoid increases posteriorly and terminates in a medially directed rounded nub, the lateral aspect of which is damaged. The coracoid likely had an expanded, bifurcate sternal articulation, of which the lateral half is missing in this specimen. The posteroventral lip of the glenoid fossa on the coracoid is pierced by a small, oval pneumatic foramen that does not contact the scapula. Immediately ventromedial to the foramen is a crescent-shaped rugosity. If this is a muscle attachment site, it would correspond most closely to the origin of the coracoid head of the m. triceps. However, Bennett (2003) inferred an origin for this muscle immediately ventral to the glenoid fossa in Campylognathoides liasicus. An anterior and presumably communicating pneumatic foramen is present on the anterior margin of the glenoid fossa ventral lip. The anterior foramen lies in a large dorsolateral excavation on the base of the acrocoracoid process. The acrocoracoid process is a sharp process distinct from the continuation of the coracoid shaft but lacks a groove separating the process from the glenoid. Though the ventral margin of the process is damaged, it does seem to have a constricted neck and a subcircular terminal expansion. There is no trace of a biceps tubercle independent of the acrocoracoid process. At the flexure in the coracoid, there is a curved rugose ridge that extends along the anterior quarter of the ventral margin of the lateral surface. This ridge corresponds to the origin of the $\mathrm{m}$. coracobrachialis as proposed by Bennett (2003).

The scapula in Sericipterus is shorter than most nonpterodactyloids, which is typically $25 \%$ longer than the coracoid (Padian and Wild, 2008). Pneumatic features are invariably present in the scapulocoracoid of pterosaurs whenever the preservation is sufficient to preserve them. In pterodactyloids, the posterior pneumatic foramen on the scapulocoracoid is a long opening shared by the scapula and coracoid almost equally. In non-pterodactyloids, this foramen is much smaller and seems to be present only on the coracoid (B. Andres, pers. observ.). 


\section{Forelimb}

Humerus-Both humeri are preserved in IVPP V14725. The left humerus is missing its dorsal distal condyle and the proximal end except for part of the base of the deltopectoral crest. The right humerus is missing its distal ventral condyle and has a damaged ulnar crest (Fig. 6E-F, Table 3). There are no visible pneumatic foramina. The humeral head and proximal end of the humerus are bowed dorsally with respect to the shaft to produce a corresponding ventral concave surface, typically found in pterosaurs. The humeral head is positioned on the humerus long axis in the horizontal plane. The head has a shallow ventral curvature in proximal view with a relative depth about $30 \%$ of the anteroposterior length. The articular surface of the humeral head is asymmetrically saddle-shaped; though concave in a horizontal plane and convex in the transverse plane, dorsal and ventral depressions in the middle of the articular surface extend from the proximal margin posterodistally and anterodistally, respectively. These depressions give the humeral head the appearance of having a constricted middle in proximal view. The posterior margin of the humeral head extends onto the ventrally oriented ulnar crest (also termed the medial process or the external, greater, or posterior tuberosity). Though damaged, the ulnar crest appears to have the shape of an inflated flange, and is distinct from the humeral head and shaft. The distal end of the ulnar crest and adjoining part of the shaft are missing. The deltopectoral crest is proximally positioned, but does not reach the proximal margin of the humerus. It is further separated from the humeral head by an emargination of its proximal margin, although a small notch in this emargination is not natural and due to a missing fragment of bone. In the sagittal plane, the deltopectoral crest extends directly anteroventrally from the shaft and curves ventrally only at the anterior-most tip. There is a slight ventral thickening to this anterior tip. The long axis of the crest is directed anteroproximally at a $110^{\circ}$ angle to the humeral shaft. In dorsal view, the shape of the deltopectoral crest outlines a tapering base that extends anteriorly as a rounded, oblong process with a very slight middle constriction. The base of the deltopectoral crest extends for about $20 \%$ the length of the humerus. Near the distal end of the crest is a crack along which there has been a slight rotation of the proximal end, giving the humerus the unnatural appearance of a posterior ridge. The humerus has a long, nearly straight shaft that lacks both a middle constriction and a supracondylar process. The dorsal surface of the shaft bears a pair of anterior and posterior muscle scars that are likely the insertions of the $\mathrm{m}$. latissimus dorsi and $\mathrm{m}$. teres major, respectively. These are followed distally by a sinusoidal rugose ridge that possibly corresponds to the origin of the lateral head of the m. triceps (Bennett, 2003). The distal ends of both humeri are damaged so that only the dorsal condyle (also termed the lateral condyle, radial condyle, or capitulum) is preserved on the right humerus, whereas the ventral condyle (also termed the medial condyle, ulna condyle, or tuberculum) is preserved on the left humerus. Through comparisons of both humeri, the distal end of the humerus can be inferred to have had a greatly expanded distal end that is crescent-shaped in cross-section. The shape of the distal end is due in large part to the dorsally and ventrally flaring entepicondyle and ectepicondyle, respectively. In anterior view, the dorsal condyle is oriented proximoventrally and is flanked by fossae on its proximal and distal margins. Not much can be seen of the ventral condyle beyond that it is smaller, and oriented subperpendicular to, the dorsal condyle.

The humerus of Sericipterus matches closely to that of other rhamphorhynchids. The shape of deltopectoral crest in this specimen has been termed 'tongue-shaped' in other rhamphorhynchids (Unwin, 2003a). However, most taxa so described have a more distinct constriction in the middle of the crest, whereas this specimen has only a very slight constriction in this area. This constriction is very pronounced in Rhamphorhynchus to the point it has been referred to as 'hatchet-shaped' and coded as an apomorphy for this taxon (Kellner, 2003). The deltopectoral crest of Sericipterus most resembles the relatively less constricted deltopectoral crest of Scaphognathus.

Antebrachium - The forearm elements of IVPP V14725 are poorly preserved and little of their morphology can be determined. They are identified as the proximal ends of the right ulna and radius, the distal end of the right ulna, and the possible distal ends of the left ulna and right radius (Fig. 6B-D, Table 3). The shafts of these elements are straight, subequal in width with respect to one another, and nearly constant in width along their preserved lengths. The terminal expansions are less than twice the widths of the shafts.

The proximal ends of the right ulna and radius are associated with one another and lay beneath the largest of the isolated teeth (Fig. 2). They are crushed flat. The proximal end of the ulna is expanded mostly on its ventral side (Fig. 6C, Table 3). The olecranon process of the ulna (also termed the crest for the insertion of $\mathrm{m}$. triceps brachii; Bennett, 2001a) is a dorsally positioned, pointed triangular process. The dorsal and ventral cotyles, for articulation with the distal condyles of the humerus are recognizable as anterior thickenings on the proximal end, but their exact margins are obscured by the crushing and slight rotation of the base of the olecranon process in this region. The middle of the anterior surface has a short, slightly ventrally curving groove surrounded by a rugose area that is identified as the biceps tubercle. This is similar to the condition found in Pteranodon but without a slight elevation. Just distal to this muscle attachment are two nutrient foramina.

The proximal right radius (Fig. 6B, Table 3 ) has part of the ventral margin of its shaft damaged, giving this bone an artificially curved appearance. Fragments of this ventral margin were found in association with the radius, confirming its original straight orientation. A pointed dorsal process gives the proximal radius a boot-shaped outline as in other pterosaurs. The cotyle for articulation with the dorsal (radial) condyle of the humerus dominates the proximal surface of the radius, but it does not extend to the ventral margin of the proximal end. The articular surface on the radius only has a single lip due to its sharing the articulation of the humerus dorsal condyle with the ulna, as in other pterosaurs. The unique shape of the articular surface of this bone facilitates its identification as the proximal end of the radius.

A $42.4 \mathrm{~mm}$ long, poorly preserved long bone is possibly a distal section of the left ulna, based on its subequal dorsal and ventral expansions and cross-sectional shape (Fig. 2). The preservation of this element is too poor to be certain of this identification thus its length is not reported in Table 3 . The distal end of the left ulna is better preserved (Fig. 6D, Table 3). The shaft has an oval cross-section that expands near its distal end. This expansion is predominantly in the ventral half. A distinct tubercle is present in the middle of the distal surface of this bone and lies between two distal concave surfaces. The dorsal and ventral ends of the posterior surface curve gently anteriorly to give the distal end a slightly semicircular cross-section. The dorsal surface is expanded and bears a groove for a flexor tendon along its ventral edge as well as a thicker dorsal half. A flat area that contacted the distal end of the radius lies ventral to this groove. The distal end of the right radius is missing the majority of its articular surface (Fig. 2) It is identified as the distal end of the right radius on the basis of its gradual dorsal expansion and a prominence on the ventral half of the anterior aspect that corresponds to the position of the anterior tubercle on the distal ends of the radii of other pterosaurs. The antebrachium in Sericipterus is identical to that of other non-pterodactyloids so far as preserved.

Manus-The carpus and metacarpus do not appear to be preserved in IVPP V14725 (see Pes below), but a small crescent shaped bone found adjacent to the distal right radius is 
likely sesamoid C of Bennett (2001a). A proximal manual phalanx is the only element representing manual digits I-III. This phalanx is a short, but narrow, bone with expanded proximal and distal ends. The distal end is round whereas the proximal end has an abductor tubercle confluent with its proximal margin.

Wing Finger-The phalanges of the wing finger (digit IV) in IVPP V14725 are represented by the left first phalanx, right second phalanx, both third phalanges, and both fourth phalanges (Fig. 6H-M, Table 3). The ratios of their lengths to the first wing phalanx are 1:0.92: $>1.16: 0.92$. The shafts of the phalanges are oval in cross-section and are about twice as wide as they are deep. These cross-sections are ventrally expanded at the ends of the wing phalanges to form more triangular interphalangeal articular surfaces. The proximal and distal ends of these wing phalanges are expanded as in most pterosaurs, but they are greatly expanded in the first two phalanges, the termini reaching at least twice the width times of their mid-section. The first and second phalanges are also more symmetrically expanded than those of the successive phalanges. All of the interphalangeal joints bear posterior processes with the exception of the proximal end of the fourth phalanx.

The complete left first wing phalanx is preserved in this specimen (Fig. 6H). The extensor tendon process is present, but not fused to the proximal margin of the phalanx. The base of this process can still be seen in Figure $6 \mathrm{H}$. The extensor tendon process has the shape of a right-angled triangle in the horizontal plane, and lacks a notch in its anterior margin. This process contributes to one third of the ventral cotyle for articulation with the distal end of the wing metacarpal. The rest of the ventral cotyle is supported by the ventral half of the proximal margin of the first phalanx proper. This cotyle terminates posteriorly in a short, proximodistally extending ridge located in the middle of the ventral surface of the phalanx. A narrow sulcus separates this ridge from the posterior half and the proximal posterior process of the phalanx. The posterior process has a nearly straight proximal margin, supporting the dorsal cotyle, and terminates in a rounded tip. The anterior margin of the proximal end of the first phalanx has a rounded longitudinal flange. When this phalanx was prepared, a small amount of anterior curvature was introduced into the shaft, but its original shape was nearly straight. Distally, this phalanx expands gradually both anteriorly and posteriorly to terminate in a strongly expanded, convex distal end. The distal end is almost as wide as the proximal end and bears a large, blunt posterior process.

The right second phalanx was found in four pieces, with the distal end lying next to the right third wing phalanx (Fig. 2, 6I). It is slightly shorter than the first wing phalanx. It also has strongly expanded ends with a relatively angular posterior process and a low anterior flange on the proximal end. The distal end has no anterior expansion, but has a posteriorly curving surface on the anterior margin of the distal end.

Portions of both third wing phalanges are preserved in this specimen. The right wing phalanx 3 is missing its proximal end (Fig. 6J) and the left phalanx is missing its distal end (Fig. 6K). Though both are incomplete, the third wing phalanx is the longest of the forelimb elements. The proximal end lacks an anterior flange but has a distinct posterior process. The left third phalanx was preserved as five separate pieces and was reconstructed with a slight sigmoidal curvature to the shaft. This curvature is almost certainly not natural. The distal end is similar in shape to the distal end of the second wing phalanx except that the distal end is only slightly wider than the shaft and bears only a small posterior process.

Both fourth wing phalanges are preserved in this specimen. The left phalanx is missing its distal end (Fig. 6L). The proximal end of the right wing phalanx four is missing its anterior and posterior margins but can be seen to have a flat proximal end as in the left wing phalanx four (Fig. 6M). The fourth wing phalanx is rather elongate and slightly longer than the second wing phalanx. Both left and right elements have a strong posterior flexure in their mid-sections. An anterior flexure in the distal end of the right phalanx is due to the reconstruction of the element. As shown by the left wing phalanx four, the proximal end is not significantly expanded, lacks a posterior process, and has only a slight anterior flange. The distal end of this phalanx (and thus of the wing-finger) is a blunt, posteroventrally directed nub. A small crack is present in this distal tip along which the ventral half has been shifted slightly to the anterior.

Wing phalanges with an oval cross-section that is twice as wide as deep have also been reported in the pterodactyloid Dsungaripterus (Bennett, 2001a), but not among non-pterodactyloid pterosaurs. The wing phalanges of Sericipterus differ from other non-pterodactyloids in having rather large proximal and distal expansions on phalanges one and two, as well as strong curvature, and lack of a proximal posterior process on the fourth wing phalanx.

\section{Pes}

There are two limb bones in IVPP V14725 that terminate in a pair of condyles. One is a complete element (Figs. 2, 6N-Q), whereas the other lacks its proximal end and is more poorly preserved (Fig. 2), but otherwise they look the same. These condyles trace out an approximate $120^{\circ}$ arc. Distinct condyles at the end of a limb bone have not been reported in pterosaurs outside of the tibia-fibulae and the penultimate manual phalanges, both of which are too different in size from these elements to be considered for their identity. In addition, these elements lack the proximal lateral expansion, cotyles for articulation with the femur, anteroposteriorly compressed shaft cross-section, large and terminally positioned condyles, or a fused fibula found in the tibiae of other pterosaurs. The presence of distal condyles is indicative of metapodial elements in other taxa. These elements, however, are relatively larger, longer, and more robust than both the metacarpals and metatarsals in other pterosaurs. Three-dimensional metapodial elements are effectively known only from the two species of Dimorphodon (Padian, 1983; Clark et al., 1998) in the non-pterodactyloid pterosaurs. When the metapodial elements in this specimen are compared to other three-dimensionally preserved metapodials and sufficiently wellpreserved two-dimensional metapodials, they are more similar to metatarsals and so are identified as such in Figures 2, 6, and Table 3 .

The length and size of the metapodial elements in IVPP V14725 are more indicative of metatarsals, which are longer than the metacarpals in non-pterodactyloids but not in pterodactyloids (B. Andres, unpubl. data). Either way, this specimen would have the largest metacarpals or metatarsals of any known non-pterodactyloid pterosaur. These elements are robust and laterally compressed, unlike the extremely delicate metacarpals that are thinner and more rounded in cross-section than the metatarsals in Dimorphodon (Padian, 1983). These elements are also perfectly straight whereas metacarpals bow anteriorly (Padian, 1983). The proximal end of the complete element is laterally compressed and almost symmetrical in outline, unlike the shallow, U-shaped cross-section of metacarpals (Padian, 1983). Furthermore, the shape of the proximal end and a slight splay to the right of the distal end matches the right metatarsal II of Dimorphodon macronyx (YPM 350). Metacarpals also have a larger proximal expansion and a smoother distal taper than the metapodial elements in this specimen that are nearly the same diameter along their length (B. Andres, pers. observ.). Both metacarpals and metatarsals have grooves on their distal ends, but only in metatarsals and the particular metapodials of IVPP V14725 do they lie in the same plane as the long axis of the 
proximal cross-section. A pair of round flanges flanks these grooves on the ventral aspect of the distal end of the metatarsals in Dimorphodon, presumably the remnants of the distal condyles. In the metacarpals, sharp tubercles instead take up this position and are more asymmetrically arranged. Though the groove reaches up onto the distal surface in IVPP V14725, the condyles maintain a ventral, subterminal position similar to the position of the pair of flanges in the metatarsals. In Dimorphodon, the ventral groove terminates at the distal margin to leave a smooth distal surface that is slightly convex in lateral view (Clark et al., 1998). In IVPP V14725, this convex distal outline is maintained but the groove incises up the distal surface to a point threequarters up the distal aspect and slightly above the midline of the shaft. Dimorphodon metacarpals, by contrast, end in terminally placed rounded bulbs (Padian, 1983), similar to the oval, convex articular surfaces found in Pteranodon (Bennett, 2001a). These distal bulbs complement the concave, circular cotyles found on the proximal surface of the proximal manual phalanges. The proximal manual phalanx found in this specimen has such a surface and therefore does not mirror the double-condyled metapodials. The metapodial elements listed as metatarsal A and B in Figures 2, 6, and Table 3 are identified as the right metatarsal II, and the distal half of another metatarsal of unknown identity, respectively.

This shape of the articular surfaces of distal metacarpals and proximal manual phalanges in pterosaurs provide a great freedom of movement for the manual digits to engage other animals or objects (Bennett, 2001b) and to be abducted while splayed laterally should they be used for quadrupedal motion (Mazin et al., 2003; Unwin, 1997). Identification of the metapodial elements in IVPP V14725 as metacarpals would preclude these functions in this individual by restricting the movement at the metacarpalphalangeal joint to a single plane. It is most probable that the metatarsals in IVPP V14725 represent a departure from the typical morphology of pterosaur metatarsals in that the ventral sulcus at the distal end of the element extended up further on to the distal articular surface to form the distinct condyles. This sulcus does not reach the dorsal surface of the metatarsal as in pterosaur outgroups. This individual probably could greatly flex the pedal digits due to the large ventral condyles. However, the ventral positioning of the condyles and the termination of the sulcus ventral to the dorsal surface probably allowed only slight hyperextension of the pedal digits.

There is also a short bone missing an articular end found near the right humerus that is tentatively identified as a pedal phalanx. This bone transitions from a laterally compressed proximal end to a smaller, subcircular cross-section at the point of its break. The phalanx is laterally compressed and gently curved along its long axis. It is identified as a pedal phalanx based on the curvature of its shaft and its closer size to the identified metatarsals than the proximal manual phalanx.

\section{PHYLOGENETIC RESULTS}

The phylogenetic analysis of Sericipterus wucaiwanensis, gen. et sp. nov., is the largest and most well-resolved analysis of basal pterosaur species to date. The analysis produced a single most parsimonious cladogram (Fig. 7) with a tree length of 145 steps (CI: 0.62, RI: 0.79, RC: 0.49) for all parsimony settings and tree search methods used. Sericipterus is placed in the Rhamphorhynchinae (sensu Unwin, 2003a) as the sister group to $A n$ gustinaripterus longicephalus. This pairing is successively more closely related to Harpactognathus gentryii, the sister group of Rhamphorhynchus muensteri and Cacubipteryx caribensis, and Dorygnathus banthensis within the Rhamphorhynchinae. Removing Sericipterus from the analysis does not alter the relationships of the remaining taxa. Bootstrap and Bremer support indices for the clades in the analysis are listed on the clado-

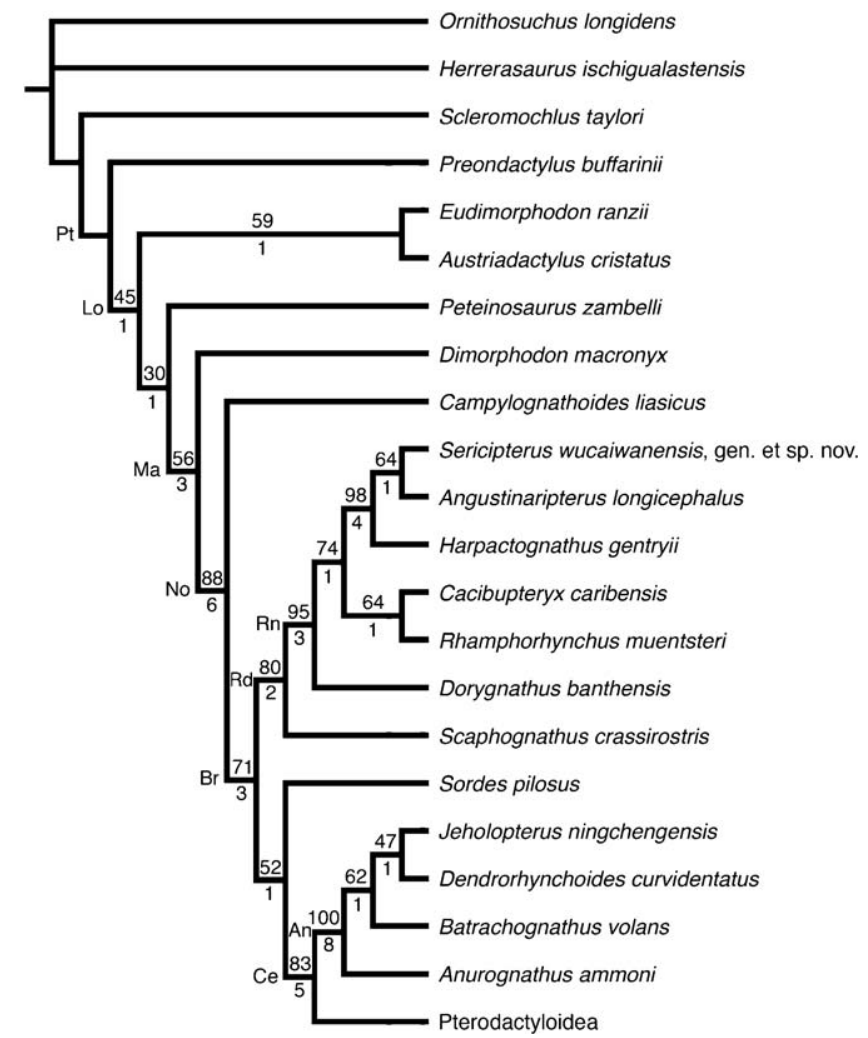

FIGURE 7. Single most-parsimonious cladogram recovered from the phylogenetic analysis of the relationships of Sericipterus wucaiwanensis, gen, et sp. nov., and the other non-pterodactyloid pterosaurs. Bootstrap and Bremer support values for the ingroup nodes are shown above and below the branches, respectively. Ornithosuchus longidens, Herrerasaurus ischigualastensis, and Scleromochlus taylori are used as outgroups. Abbreviations: An, Anurognathidae; Br, Breviquartossa; Ce, Caelidracones; Lo, Lonchognatha; Ma, Macronychoptera; No, Novialoidea; Pt, Pterosauria; Rd, Rhamphorhynchidae; Rn, Rhamphorhynchinae.

gram in Figure 7. The support for most clades within the analysis is relatively high considering the incompleteness of many taxa: bootstrap scores are below $50 \%$ only for the preferred sister-group relationship between Jeholopterus ningchengensis and Dendrorhynchoides curvidentatus, as well as the two basalmost backbone nodes within the Pterosauria; nodes with Bremer indices of one are present in the Anurognathidae (sensu Kellner, 2003; Unwin, 2003a) and Rhamphorhynchinae, for the sister group of Sordes pilosus and Caelidracones (sensu Unwin 2003a,) as well as for the three basal-most nodes within the Pterosauria.

Sericipterus is firmly placed within the Rhamphorhynchidae Owen, 1870, requiring at least 16 steps to place it anywhere else on the cladogram outside of this group. Its sister-group relationship to Angustinaripterus is supported by a single unambiguous character state change: the gain of an elliptical cross-section of the rostral process of the skull (character 2, state 1). The skull of Sericipterus broadly resembles the skull of Angustinaripterus differing mainly in being larger with more robust skull elements and otherwise having more extreme versions of the morphology that distinguish Angustinaripterus from the other non-pterodactyloid pterosaurs. Two other changes might also support this node: the ventral orientation of the jugal posterior process (character 19, state 1 ) and the lingual curvature of the teeth (character 33, state 1). However, the sister group to this node, Harpactognathus, is 
preserved only as a rostrum missing its teeth and so these characters remain ambiguously optimized on the cladogram. Despite the fact that these three species share only parts of the skull in their preservation, their grouping is well supported. This clade of three species has the second highest bootstrap score in the analysis, and all four characters that support it contribute to its Bremer score: expansion of the rostrum (character 6, state 1), appearance of a premaxillary crest (character 7 , state 1 ), undulating jaw margins (character 30, state 1), and ventrolateral orientation of teeth (character 37, state 1). Harpactognathus was previously referred to the Scaphognathinae (Carpenter et al., 2003; Unwin, 2003a). The sister-group relationship of these three species to the sister group of Rhamphorhynchus and Cacubipteryx also has a branch length of four steps but with much lower support indices for this clade. Unlike the two previously mentioned nodes, the character states that support this node are not preserved in each of the included taxa: all four characters cannot be assessed in Cacubipteryx and one character in Harpactognathus (character 38) as well as Angustinaripterus and Harpactognathus (character 63). The addition of Dorygnathus to these taxa completes the circumscription of the Rhamphorhynchinae: Dorygnathus banthensis, Rhamphorhynchus muensteri, their most recent common ancestor, and all of its descendents (Unwin, 2003a). This node has one of the longest subtending branches in the analysis, with eight steps: advent of subparallel dorsal and ventral margins of the external naris (character 10, state 1); elongate antorbital fenestra (character 14, state 1); oblique mandible articulation condyles (character 21, state 1); anterodorsal orientation of the mandible tip (character 28, state 1); strongly curved teeth (character 32, state 1); procumbent mesial teeth (character 36, state 1 ); teeth not reaching the mandible anterior margin (character 44, state 1); and pneumatic cervical neural arches (character 45 , state 1 ). The sister group of the Rhamphorhynchinae, and the only remaining rhamphorhynchid, is Scaphognathus crassirostris. It is supported in this position by the dorsal displacement of the external naris (character 13, state 1) and the elongation of the teeth (character 34 , state 1$)$.

The results of the phylogenetic analysis of Sericipterus and the other non-pterodactyloid pterosaurs are equal parts novel results and support for previous results. Relationships of these taxa have been most clearly delimited in the analyses by Kellner (2003) and Unwin (2003a, 2003b). Unwin (1995) provided the first analysis and Bennett (2007) provides a recent analysis of non-pterodactyloid pterosaur relationships. Unwin (1995) and Bennett (2007) are identical to Unwin (2003a, 2003b) except for the basal-most position of the Anurognathidae in Bennett (2007). Like Unwin (2003a:fig. 7, 2003b:fig. 2), the current analysis recovers both Preondactylus buffarinii Wild, 1983, as the most basal pterosaur, and a monophyletic Rhamphorhynchidae. It differs in that Sordes is sister to the Caelidracones. Because Sordes was used as a specifier for Unwin's (2003a) definitions of the Rhamphorhynchidae and Scaphognathinae, the placement of Sordes outside of the traditional rhamphorhynchid clade results in both clades being paraphyletic with respect to the pterodactyloids and having the same circumscription as each other and the Breviquartossa. The Rhamphorhynchidae in the context of the current analysis refers to the traditional grouping; Sordes was originally referred to the Dimorphodontidae by Sharov (1971). Kellner (2003:fig. 1) placed the different rhamphorhynchids and Sordes along the backbone of his cladogram with Rhamphorhynchus as sister group to the Pterodactyloidea, and Scaphognathus and Dorygnathus at the third and fourth basal nodes, respectively. The current analysis recovered a fully resolved Anurognathidae, matching the results of Kellner (2003) but with the addition of Jeholopterus as the sister group to Dendrorhynchoides. Unwin (2003b) recovered an unresolved polytomy for the internal relationships of the Anurognathidae. Despite notable differences, the current analysis is in agreement with Unwin (2003a, 2003b),
Kellner (2003), and Bennett (2007) for the branching order of $\mathrm{Di}$ morphodon macronyx, Campylognathoides liasicus, and Rhamphorhynchus with respect to the Pterodactyloidea.

The current phylogenetic analysis presents a number of novel results. These results are most discernable in the concordance of the stratigraphic order with the branching order of the taxa recovered in the analysis. Unlike previous work, the current analysis recovered all of the Triassic pterosaurs at the basal-most nodes followed by the earliest Jurassic Dimorphodon, the late Early Jurassic Novialoidea (sensu Kellner, 2003), as well as the Late Jurassic Sordes and Caelidracones group. Previous results had later Jurassic taxa interspersed among the Triassic forms and therefore required the radiation of all major pterosaur groups except for the Breviquartossa before the first pterosaur appears in the fossil record. The most extreme version is the topology from Kellner (2003), in which three of the at most four basal-most taxa appear in the Late Jurassic, requiring ghost lineages of at least 50 million years for all three. The concordance with stratigraphy in the current analysis is realized primarily through the novel results of a paraphyletic Dimorphodontidae (sensu Unwin, 2003a), a polyphyletic Campylognathoididae (sensu Unwin, 2003a), and a sister-group relationship of the Anurognathidae with respect to the Pterodactyloidea.

Unwin (2003b) and Kellner (2003) address the monophyly of the Dimorphodontidae (sensu Unwin, 2003a), that is, the sister-group relationship of Dimorphodon and Peteinosaurus. Unwin (2003b) placed the two species in a sister-group relationship. Kellner (2003) recovered both in an unresolved trichotomy with the Novialoidea, and therefore is equivocal with respect to their relationship to one another. The current analysis did not recover a monophyletic Dimorphodontidae but does place Dimorphodon and Peteinosaurus as adjacent terminal taxa along the backbone of the cladogram, with Dimorphodon closer to pterodactyloids. This is one of two novel results that split a previous sister group of a Triassic species and a younger species.

The other example is the polyphyly of the Campylognathoididae. Analyses by Kellner (2003) and Unwin (2003b) both supported a closer relationship between Eudimorphodon ranzii and Campylognathoides than to all other non-pterodactyloids with the exception of Austriadactylus cristatus, which was placed as a sister taxon to Eudimorphodon within the Campylognathoididae by Unwin (2003b). Eudimorphodon and Campylognathoides share overall skull shapes, similar mandible tips (character 28, state 2 ; character 44, state 1 ), identical deltopectoral crests (character 54, state 2), similarly-shaped sterna (character 50, state 1), a second wing phalanx longer than the ulna (character 64, state 1 ), and a femur less than twice the metacarpal IV length (character 70 , state 1 ). These were, however, found to be homoplastic (characters $28,44,54$, and 64 ) or plesiomorphic (character 50) in the current analysis. A monophyletic Campylognathoididae would require six additional steps in the current analysis. The current analysis supports a sister group relationship of the Late Triassic Eudimorphodon and Austriadactylus, adjacent to the other Triassic species as the second basal-most node in the cladogram, and Campylognathoides farther up the tree due to the addition of new characters (characters 39,40, and 41), and recoding of previouslycoded characters (characters 9, 29, 31, 35, 68, and 69).

The close relationship of Eudimorphodon and the late Early Jurassic Campylognathoides and its placement close to Rhamphorhynchidae and Pterodactyloidea found in all previous analyses has been the main source of stratigraphic incongruence. The placement of Eudimorphodon as sister to Campylognathoides extends the temporal range of the Campylognathoididae to the Late Triassic, implying the divergence of all pterosaur groups more basal than the Campylognathoididae before pterosaurs first appear in the fossil record. These results suggest that future phylogenetic analyses of basal pterosaur relationships should not use the Campylognathoididae as a terminal taxon, as did Unwin 
(1995, 2003a) and Bennett (2007), because their monophyly is rejected (see Kellner (2004) for discussion of a priori supraspecific taxa in pterosaur phylogenetic inference).

Perhaps the most drastic difference between the current and previous analyses is the position of the Anurognathidae as the sister group of the Pterodactyloidea. Previous work placed the Rhamphorhynchidae, or at least Rhamphorhynchus, as a sister taxon to the Pterodactyloidea. The Anurognathidae have most often been placed as the basal-most pterosaur group (Kellner, 2003; Bennett, 2007), though Unwin (2003a) places the group slightly less basal in his analysis as the sister taxon to Campylognathoididae plus Breviquartossa. The Anurognathidae are the last group of non-pterodactyloid pterosaurs to appear (and disappear) from the fossil record, thus placing them as the basalmost pterosaur group creates the longest ghost lineage in the Pterosauria of at least 70 million years. The Anurognathidae have the longest branch and the greatest support for their monophyly in this and other analyses of basal pterosaur relationships, but previously have had much weaker support for their interrelationships. They are generally regarded as one of the most derived and unusual pterosaur groups (Bennett, 2007). This is due in most part to the highly derived shape of their skulls, which are very short and tall, dominated by extremely large orbits and a wide gape. Characters of the skull provided most of the support for a basal position of the Anurognathidae in previous work. In the current analysis, the sister group of the Anurognathidae and the Pterodactyloidea is one of the best-supported nodes and includes only a single skull character in its support. It would appear, therefore, that the extreme modification of the anurognathid skull is a functional complex that has obfuscated their relationships. It should be appreciated that Unwin (2003b) noted the reduction of cervical ribs and fewer caudal vertebrae (Unwin, 2003b:characters 26 and 27) present in the Anurognathidae that could possibly support a closer relationship to the Pterodactyloidea.

New anurognathid specimens and evaluation of previous characters suggest that the characters of the skull and postcrania previously coded as absent are indeed present, or at least cannot be coded, in anurognathid specimens. Bennett (2007) recently analyzed the phylogenetic relationships of the Anurognathidae to other major basal pterosaur groups recovering the Anurognathidae as the basal-most clade. The current analysis also contains higher support for the position of the Anurognathidae using relatively fewer skull characters for the placement of this taxon than the analyses of Kellner (2003) or Unwin (2003a, 2003b). Among the 21 characters used in Bennett (2007), five do not contradict the results of the current analysis, four are thought here to be related to preservation, four are regarded to be autapomorphies, three are considered to be inapplicable, two are coded differently, and one was not coded in any anurognathid species. This leaves only two characters supporting a more basal phylogenetic position for Anurognathidae than as a sister taxon to the Pterodactyloidea.

Because the posterior region of the skull in the holotype of $A$. ammoni is not preserved and all other known anurognathid skulls are flattened dorsoventrally, the orientation of the quadrate and the shape of the skull (Bennett, 2007:character 6) and the shape of the mandible near the jaw articulation, cannot be unambiguously coded (Bennett, 2007: character 15). Furthermore, the coding of the capability of flexion and extension of the interphalangeal wing joints in the Anurognathidae and the outgroup (Bennett, 2007:character 21) may be related to similarities in the disarticulation of anurognathid individuals, especially considering that these joint surfaces are flat. A short and deep rostrum (Bennett, 2007:character 9), absent elongated rostral part of the skull (Bennett, 2007:character 17), and a short pteroid (Bennett, 2007:character 20) are optimized here as apomorphic conditions for the Anurognathidae because the condition in the outgroups more closely resembles that of other pterosaur groups, or is inapplicable in the case of the pteroid. The presence of a narrow sternum (Bennett, 2007:character 19) is apomorphic for A. ammoni, because this analysis follows Bakhurina and Unwin (1995) in identifying a broad sternum in Batrachognathus volans. The current analysis agrees with Bennett (2007:fig. 7) that the posterior process of the premaxilla interfingers between the frontals (Bennett, 2007:character 10), and with Unwin (2003a, 2003b) that the manual phalanges are relatively more robust than the pedal unguals (Bennett, 2007: character 3), contrary to the coding in Bennett (2007). Finally, the shape of the external naris (Bennett, 2007:character 11), the orientation of the nasal process of the maxilla (Bennett, 2007:character 12), and the maxilla-nasal contact length (Bennett, 2007:character 13) cannot be coded in anurognathids because the maxilla does not contact the nasal and the external naris and antorbital fenestra are combined into a single confluent opening, the nasoantorbital fenestra.

This publication is the first to identify the presence of a nasoantorbital fenestra in the Anurognathidae, which was previously only reported in the Pterodactyloidea. In the first description of an anurognathid pterosaur, the holotype of Anurognathus (BSP 1922.I.42), Döderlein (1923) figured three elements anterior to or within the orbit: an isolated process within the orbit, a disarticulated process contacting his 'adlacrimal,' and the maxilla. In his reconstruction, he ignored the isolated process in the orbit and reconstructed an ascending process of the jugal and the maxilla outlining the borders of the orbit, antorbital fenestra, and external naris. Wellnhofer (1975:fig. 38) later figured the isolated process as an anteriorly displaced descending process of the lacrimal, the disarticulated process as the ascending process of the maxilla contacting the nasal, and Döderlein's maxilla as the premaxilla. This meant that only the borders of the antorbital fenestra and external naris were outlined, and that the previously identified orbit and antorbital fenestra were instead the antorbital fenestra and external naris, respectively. With the description of a new, more complete specimen Anurognathus, Bennett (2007) reinterpreted the skull of the holotype. Wellnhofer's (1975) premaxilla was recognized, and the two processes thought to represent the ascending process of the maxilla and/or the ascending process of the jugal and part of the jugal/nasal process. The isolated process in the orbit is labeled the ascending process of the maxilla in his figure 10. Currently, the only possible evidence of a separate external naris and antorbital fenestra in the holotype of Anurognathus is an isolated process displaced into the orbit that has been identified alternatively as part of the lacrimal, the ascending process of the maxilla, a jugal-nasal process, or just ignored. Bennett's (2007) new specimen provides a more complete skull preserved in dorsal view. Bennett (2007) reconstructs the skull dominated by the extremely large orbits that have shifted the jugal and its ascending process far anteriorly and in turn reduced the lateral exposure of the maxilla and any anterior fenestrae to a small part of the anterior margin of the skull. The maxilla continues posteriorly along the medial margin of the jugal. This reconstruction is almost certainly correct, but the evidence for an ascending process of the maxilla and a therefore separated external naris and antorbital fenestra falls to a small process present only on the right side of the skull. This small bar of bone is not visible in the photo in figure 3 but is present as an impression. It cannot be seen to contact either the identified jugal-nasal process or the maxilla (Bennett, 2007). Because the evidence for a separate external naris and antorbital fenestra in Anurognathus relies on the identification of a couple of isolated bones assumed to be processes, the current analysis regards the presence of a nasoantorbital fenestra in this species as equivocal.

Specimens of Batrachognathus and Jeholopterus confirm that the ascending processes of the maxilla are absent and that the external naris and antorbital fenestra are confluent in these 
anurognathids. Though the skull of the holotype of Batrachognathus (PIN 13) is preserved in ventral view, no ascending process can be observed between the premaxillary bar and the ascending process of the jugal as identified by Bennett (2007:391). Furthermore, the premaxilla has become disarticulated from the maxilla so that the length from the anterior tip of the maxilla to the ascending process of the jugal is only two $\mathrm{mm}$ in length (Rjabinin, 1948:fig. 1, pl. 1). This is scarcely long enough to support a separate process even if it had been broken off. Another specimen of Batrachognathus (PIN 2585/4) and a specimen referred to Jeholopterus by Ji and Yuan (2002) preserve articulated skulls in dorsal view (Ji and Yuan, 2002:pl. 2A). These specimens confirm that there is only one fenestra anterior to the orbit and there are no traces of processes between the orbit and premaxillary bar. Therefore, a confluent external naris and antorbital fenestra is coded as present in Batrachognathus and Jeholopterus, uniting the Anurognathidae and Pterodactyloidea in the present analysis. Despite the coding differences between the current analysis and Bennett (2007), enforcing the basal-most position for the Anurognathidae in the current analysis would require five more steps than enforcing the sister-group relationship with the Pterodactyloidea in Bennett (2007). The support for the novel position of the Anurognathidae in the current analysis extends beyond the recoding of previous characters.

\section{DISCUSSION}

The three-dimensional preservation of Sericipterus wucaiwanensis, gen. et sp. nov., and its two closest relatives Angustinaripterus and Harpactognathus reveal morphology not typically visible in pterosaur specimens. In Sericipterus, the only member of this clade with preserved postcrania, one of the most interesting new aspects of morphology is the distinct intervertebral articulations of the cervical vertebrae. Though previously unreported, it is proposed here that the morphology of these articulations is the typical condition for non-pterodactyloid pterosaurs and that a similar morphology can be found where there is sufficient preservation of these taxa. It has been often figured, but little discussed, that the cervical vertebrae of non-pterodactyloid pterosaurs have posterior condyles with a distinct rounded, biconvex appearance in ventral view (e.g., Arthaber, 1921:fig. 17; Bonde and Christiansen, 2003:fig. 9; Owen, 1870:pl. 17; Padian and Wild, 2008:pl. 1 fig. 5, pl. 4 fig. 3, pl. 7 fig. 2, pl. 8 fig. 1, pl. 9 fig. 4; Plieninger, 1907:fig. 10; Wellnhofer, 1975:fig. 26a) as found in Sericipterus. These structures are not distinct processes but are instead paired projections of the posterior condyle and ventrolateral extensions of a curved articular surface. These projections become better defined posteriorly in the cervical series of non-pterodactyloids and are usually first visible at cervical 5.

These structures have been twice termed 'exapophyses' in Rhamphorhynchus (Bond and Christiansen, 2003) and Dorygnathus (Padian and Wild, 2008). However, no homology statement has been made with respect to the pair of distinct processes ventrolateral to the posterior condyle in ornithocheiroid and ctenochasmatid pterodactyloids, most often termed postexapophyses (Williston, 1897) and at times, 'exapophyses' (Williston, 1897; Eaton, 1910; Bennett, 1989; Buffetaut et al., 1997; Company et al., 1999; Henderson and Peterson, 2006; Witton and Naish, 2008), or processus ventrolaterales (Frey and Martill, 1996). These processes were originally described by Owen (1859) as short obtuse processes, thick diverging apophyses, rudimentary processes, and transverse processes in Cambridge Greensand pterosaurs, before they were named postexapophyses by Williston (1897). Recently, ctenochasmatid pterodactyloids have been demonstrated to have independently developed postexapophyses (Andres and $\mathrm{Ji}, 2008$ ), illustrating that these structures developed on multiple occasions. To avoid confusion with the preexapophyseal articulations that have also been inter- mittently termed 'exapophyses' (Williston, 1897; Eaton, 1910), Bennett (2001a:38) defined postexapophyses as "the accessory processes on the posterior end of the cervical vertebrae ventrolateral to the condyle." Following this definition, the nonpterodactyloid pterosaurs do not have postexapophyses. Instead of having distinct processes bearing accessory articular surfaces separated from the posterior condyle by a groove, the posterior condyles of non-pterodactyloid cervicals have a single confluent articular surface extended onto posterolateral ridges of the centrum. These structures should not be termed 'exapophyses,' because they are not distinct processes and do not share any similarity with the structures that have been traditionally termed 'exapophyses' (besides their position). The non-pterodactyloid condition is termed here 'postlateral projections,' analogous, but not homologous, to the processi postlaterales formed in a similar manner in modern grebes, gannets, and flamingos (Baumel and Witmer, 1993).

In his discussion of the evolution of postexapophyses, Bennett (2001a) suggested that the formation of processes to provide additional leverage for cervical musculature preceded the extension of the articular surface of the condyle onto them. Sericipterus and the other non-pterodactyloids have extensions of the articular surface of the condyle without the formation of distinct processes. Considering that the phylogenetic positions of the Ornithocheiroidea and Ctenochasmatidae lie relatively close to the base of the Pterodactyloidea (Unwin, 1995, 2003a; Andres and Ji, 2008:fig. 5), it is possible that the extension onto them of the articular surface of the posterior condyle preceded the formation of postexapophyses in this transformation series rather than the other direction.

One non-pterodactyloid cervical vertebra appears to bear true postexapophyses. In his discussion of the vertebral characters of the pterosaurs, Owen (1859) described and figured a cervical vertebra from the Mid-Jurassic Stonesfield Slate referred to Pterodactylus (Rhamphocephalus) bucklandi. Though he does not mention any processes ventrolateral to the centrum in the description of this specimen, he labels a pair of such processes with the same label he used to denote the diverging processes he identified in the Cambridge Greensand material (Owen, 1859:pl.10 figs. 38 and 39). This specimen corresponds to one of two vertebrae curated at the Natural History Museum, London, under the number of NHM 40126e. This vertebra bears distinct processes ventrolateral to the posterior condyle that are separated from the condyle by a groove. In all other respects, the specimen is a typical non-pterodactyloid vertebra. It is currently more parsimonious that this individual developed postexapophyses independently of the ornithocheiroids. It is noteworthy to argue that this vertebra is one of the largest found in non-pterodactyloids, albeit only a couple of millimeters shorter than those of Sericipterus, and the development of distinct postexapophyses may be partly correlated with size.

Postlateral projections are proposed as the typical condition for non-pterodactyloid cervical series based upon the recognition of one or more features seen in the other two-dimensional non-pterodactyloid specimens: a rounded, biconvex appearance of the posterior condyle in ventral view, a concave surface on the posteroventral end of the centrum, and dorsal and/or ventral lips on the articular surface in isolated vertebrae. In addition, these features become more clearly developed at the base of the neck, from the fifth cervical onwards. Postlateral projections can be distinguished from postexapophyses because the latter are separated from one another by the broad, oval posterior condyle. It should be noted that although the posterior articular surfaces of the non-pterodactyloid cervical vertebrae are curved ventrally, the anterior articular surfaces are not. Given the distinct shapes of these articular surfaces, the straight centra, and robust lips on the posterior condyles, the articulation of these cervical vertebrae with one another would have extended 
the head and neck above the dorsal vertebral series. The aforementioned increased angle in zygpapophyseal articulations and posteriorly increasing robusticity of these features would further correspond to the areas of greatest curvature in a dorsally reflected neck. This may represent a unique means by which basal pterosaurs were able to extend their head and neck above the trunk.

Another distinctive aspect of non-pterodactyloid pterosaur cervicals is the peculiar structure of the zygapophyses. As shown by the element identified as cervical 5 , some of the cervicals possess robust zygapophyses that have nearly vertical articular surfaces, presumably greatly restricting the lateral movement possible between cervicals possessing these kind of zygapophyses. This morphology is difficult to identify in flattened specimens but is visible in well-preserved specimens such as Dimorphodon weintraubi, Dimorphodon macronyx, and Dorygnathus (J. Hopson and J. Clark, pers. observ.) as well as specimens of Rhamphorhynchus (B. Andres, pers. observ.).

Sericipterus and its two closest relatives are unusual in their large size. The minimum wingspan estimate of $1.73 \mathrm{~m}$ and minimum skull length estimate of $210 \mathrm{~mm}$ would make Sericipterus at least the second largest, and most likely the largest, nonpterodactyloid species known. The holotype of Campylognathoides zitteli (SMNS 9787) with a wingspan of $1.75 \mathrm{~m}$ and a specimen of Dimorphodon macronyx (NHM 41212) with a skull length of $215 \mathrm{~mm}$ are the only specimens that are larger in these measurements. However, the minimum estimates for Sericipterus exclude missing portions of some elements, and even conservative estimates of these missing portions would make the holotype of Sericipterus wucaiwanensis a larger individual. In addition, these two specimens are osteological adults, unlike the holotype Sericipterus, which may have reached an even larger size when it had reached osteological maturity. C. zitteli and D. macronyx also have a relatively elongate wing finger and skull, respectively, compared to the rest of skeleton. For other skeletal elements (e.g., prenarial rostrum, cervical and dorsal vertebrae, humerus), Sericipterus is the largest non-pterodactyloid pterosaur. The preserved portions of the skulls of Angustinaripterus and Harpactognathus are a little smaller than the corresponding portions of Sericipterus.

Sericipterus and its two closest relatives, Angustinaripterus and Harpactognathus, comprise a clade of large-bodied, robust nonpterodactyloid pterosaurs. They are distinct from other nonpterodactyloids in that their skulls bear a variety of distinct crests, ridges, processes, and highly curved teeth; and at least Sericipterus has postcrania with a tightly associated cervical series, expanded ends of the proximal wing phalanges, and larger oval cross-sections of the wing phalanges not found in other nonpterodactyloid pterosaurs. These species include some of the few pterosaurs found in alluvial sediments and represent the majority of non-pterodactyloid species from those sediments. Pterosaurs are rarely found in terrestrial sediments and those that are usually occur in lacustrine sediments (e.g., Sordes, most anurognathids, and Jehol biota pterosaurs). With the large majority of the pterosaur fossil record concentrated in marine environments (Kellner, 1994), it is not surprising that most pterosaurs have been suggested to be piscivorous (e.g., Sereno, 1991; Wellnhofer, 1991; Hazlehurst and Rayner, 1992; Unwin, 1996, 2005; Howse et al., 2001; Bennett, 2007). However, Sericipterus and its two closest relatives lack the skull features associated with piscivory (Sereno, 1991), skimming (Hazlehurst and Rayner, 1992), or grab-feeding from a water surface (Wellnhofer, 1975) found in other nonpterodactyloids (but see Humphries et al., 2007, for a discussion of the unlikely common use of skim feeding in pterosaurs). Also, the rather broad rostrum and highly curved teeth with their cross-sectional long axes oriented at an oblique angle to the sagittal plane found in Sericipterus would have incurred additional resistance when interacting with a water surface. Similar teeth reported in terrestrial deposits of the older Middle Jurassic (Callovian) Balabansai Svita of adjacent Kyrgyzstan (Averianov et al., 2005) and in deltaic deposits of the younger earliest Cretaceous (Berriasian) of Morocco (Knoll, 2000) may be the oldest and youngest occurrences of this clade. Sericipterus, Angustinaripterus, and Harpactognathus likely represent a clade of pterosaurs that lived and fed in the terrestrial settings in which they were preserved.

\section{ACKNOWLEDGMENTS}

We thank Wang H.-J. (IVPP, Beijing), Huo Y. (IVPP, Beijing), Tang J.-L. (IVPP, Beijing), Zhao X. (IVPP, Beijing), the late W. Downs (Museum of Northern Arizona, Flagstaff, Arizona), J. Choiniere (George Washington University, Washington, D.C.), C. Sloan (National Geographic Society, Washington, D.C.), C. Forster (George Washington University, Washington, D.C.), D. Eberth (Royal Tyrell Museum of Palaeontology, Drumheller, Alberta), R. Hauff (Urwelt-Museum Hauff), and N. Frankfurt (American Museum of Natural History, New York) for organization and assistance in the field. Data were provided by S. C. Bennett (Fort Hays State University, Hays, Kansas) and G. Dyke (University College of Dublin, Dublin, Ireland). Jacques Gauthier (Yale Peabody Museum, New Haven, Connecticut) provided comments on the manuscript. Funding for this research was provided in part by the Jurassic Foundation, National Geographic, National Science Foundation Division of Earth Sciences, Hilmar Sallee Bequest, Chinese Academy of Sciences, National Science Foundation of China, and Sigma Xi Grant-in-Aid.

\section{LITERATURE CITED}

Andres, B., and J. M. Clark. 2005. Jurassic Pterosaurs from Xinjiang, China: The earliest pterodactyloid and the origins of the group. Journal of Vertebrate Paleontology 25(3, Supplement):32A.

Andres, B., and Q. Ji. 2006. A new species of Istiodactylus (Pterosauria, Pterodactyloidea) from the Lower Cretaceous of Liaoning, China Journal of Vertebrate Paleontology 26:70-78.

Andres, B., and Q. Ji. 2008. A new pterosaur from the Liaoning Province of China, the phylogeny of the Pterodactyloidea, and convergence in their cervical vertebrae. Palaeontology 51:1-17.

Arthaber, G. von. 1921. Studien über Flugsaurier auf Grund der Bearbeitung des Wiener Exemplares von Dorygnathus banthensis Theod. sp. Denkschriften Akademie der Wissenschaften in Wien Mathematisch-naturwissenschaftliche Klasse 97:391-464.

Averianov, A. O., T. Martin, and A. A. Bakirov. 2005. Pterosaur and dinosaur remains from the Middle Jurassic Balabansai Svita in the Northern Fergana Depression, Kyrgyzstan (Central Asia). Palaeontology 48:135-155.

Bakhurina, N., and D. M. Unwin. 1995. A survey of pterosaurs from the Jurassic and Cretaceous of the Former Soviet Union and Mongolia Historical Biology 10:197-245.

Baumel, J. J., and L. M. Witmer. 1993. Osteologia; pp. 45-132 in J. J. Baumel (ed.), Handbook of Avian Anatomy. Publications of the Nuttal Ornithological Club, Cambridge, U.K.

Bennett, S. C. 1989. A pteranodontid pterosaur from the early Cretaceous of Peru, with comments on the relationships of Cretaceous pterosaurs. Journal of Paleontology 63:669-677.

Bennett, S. C. 1993. The ontogeny of Pteranodon and other pterosaurs. Paleobiology 19:92-106.

Bennett, S. C. 1994. Taxonomy and systematics of the Late Cretaceous pterosaur Pteranodon (Pterosauria, Pterodactyloidea). Occasional Papers of the Natural History Museum, University of Kansas 169:1-70.

Bennett, S. C. 1996. Year-classes of pterosaurs from the Solnhofen Limestone of Germany: taxonomic and systematic implications. Journal of Vertebrate Paleontology 16:432-444.

Bennett, S. C. 2001a. The osteology and functional morphology of the Late Cretaceous pterosaur Pteranodon: Part I. General description of osteology. Paleontographica Abteilung A 260:1-112. 
Bennett, S. C. 2001b. The osteology and functional morphology of the Late Cretaceous pterosaur Pteranodon: Part II. Size and functional morphology. Paleontographica Abteilung A 260:113-153.

Bennett, S. C. 2003. Morphological evolution of the pectoral girdle of the pterosaurs: myology and function; pp. 191-215 in E. Buffetaut and J.-M. Mazin (eds.), Evolution and Palaeobiology of Pterosaurs. Geological Society, London, Special Publications 217.

Bennett, S. C. 2007. A second specimen of the pterosaur Anurognathus ammoni. Paläontologische Zeitschrift 81:376-398.

Bonde, N., and P. Christiansen. 2003. The detailed anatomy of Rhamphorhynchus: axial pneumaticity and its implications; pp. 217-232 in E. Buffetaut and J-M. Mazin (eds.), Evolution and Palaeobiology of Pterosaurs. Geological Society, London, Special Publications 217.

Buffetaut, E. 1996. The "ornithurine" from the Lower Cretaceous of Changji, Xinjiang (China): bird or pterosaur? Cretaceous Research 17:505-508.

Buffetaut, E., Y. Laurent, J. LeLoeuff, and M. Bilotte. 1997. A terminal Cretaceous giant pterosaur from the French Pyrenees. Geological Magazine 134:553-556.

Campos, D. A., and Kellner, A. W. A. 1985b. Panorama of the flying reptiles study in Brazil and South America. Anais da Academia Brasileira de Ciencias 57:453-466.

Carpenter, K., D. Unwin, K. Cloward, C. Miles, and C. Miles. 2003. A new scaphognathine pterosaur from the Upper Jurassic Morrison Formation of Wyoming, USA; pp. 45-54 in E. Buffetaut and J.-M. Mazin (eds.), Evolution and Palaeobiology of Pterosaurs. Geological Society, London, Special Publications 217.

Clark, J. M., X. Xu, C. Forster, and Y. Wang. 2004a. A Middle Jurassic 'sphenosuchian' from China and the origin of the crocodylian skull. Nature 430:1021-1024.

Clark, J. M., J. A. Hopson, R. Hernandez, R. D. E. Fastovsky, and M. Montellano. 1998. Foot posture in a primitive pterosaur. Nature 391:886-889.

Clark, J. M., X. Xu, C. Forster, Y. Wang, and D. Eberth. 2004b. New discoveries from the Middle-to-Upper Jurassic Shishugou Formation, Xinjiang, China. Journal of Vertebrate Paleontology 24(3, Supplement):46A.

Clark, J. M., X. Xu, D. E. Eberth, C. A. Forster, M. Machlus, S. Hemming, Y. Wang, and R. Hernandez. 2006. The Middle-to-Late Jurassic terrestrial transition: new discoveries from the Shishugou Formation, Xinjiang, China; pp. 153 in P. M. Barrett and S. E. Evans (eds.), Ninth International Symposium on Mesozoic Terrestrial Ecosystems and Biota, Manchester, UK. Cambridge Publications. Natural History Museum, London, UK.

Company, J., J. I. Ruiz-Omenaca, and X. P. Suberbiola. 1999. A long-necked pterosaur (Pterodactyloidea, Azhdarchidae) from the Upper Cretaceous of Valencia, Spain. Geologie en Mijnbouw 78:319-333.

Czerkas, S. A., and Q. Ji. 2002. A new rhamphorhynchoid with a headcrest and complex integumentary structures; pp. 14-41 in S. J. Czerkas (ed.), Feathered Dinosaurs and the Origins of Flight. The Dinosaur Museum, Blanding, Utah.

Dalla Vecchia, F. M., R. Wild, H. Hopf, and J. Reitner. 2002. A crested rhamphorhynchoid pterosaur from the Late Triassic of Austria. Journal of Vertebrate Paleontology 22:196-199.

Döderlein, L. 1923. Anurongathus ammoni, ein neuer Flugsaurier. Sitzungberichte der Mathematisch-Physikalischen Klasse der Bayerischen Akademie der Wissenschaften 1923:117-164.

Eaton, G. F. 1910. Osteology of Pteranodon. Memoirs of the Connecticut Academy of Arts and Sciences 2, $38 \mathrm{pp}$.

Frey, E., and Martill, D. M. 1996. A reappraisal of Arambourgiana (Pterosauria, Pterodactyloidea): one of the world's largest flying animals. Neues Jahrbuch für Geologie und Paläontologie, Abhandlungen 199:221-247.

Galton, P. M. 1981. A rhamphorhynchoid pterosaur from the Upper Jurassic of North America. Journal of Paleontology 55:1117-1122.

Gasparini, Z., M. Fernandez, and M.de laFuente. 2004. A new pterosaur from the Jurassic of Cuba. Palaeontology 47:919-927.

Hazlehurst, G. A., and J. M. V. Rayner. 1992. Flight characteristics of Triassic and Jurassic Pterosauria: an appraisal based on wing shape. Paleobiology 18:447-463.

Henderson, M. D., and J. E. Peterson. 2006. An azhdarchid pterosaur cervical vertebra from the Hell Creek Formation (Maastrichtian) of Southeastern Montana. Journal of Vertebrate Paleontology 26:192-195.
Howse, S. C. B. 1986. On the cervical vertebrae of the Pterodactyloidea (Reptilia: Archosauria). Zoological Journal of the Linnean Society 88:307-328.

Howse, S. C. B., A. R. Milner, and D. M. Martill. 2001. Pterosaurs; pp. 324-335 in D. Martill and D. Naish (eds.), Dinosaurs of the Isle of Wight. The Paleontological Association, London, Palaeontological Association Field Guide to Fossils, 10.

Humphries, S., R. H. Bonser, M. P. Witton, and D. M. Martill. 2007. Did pterosaurs feed by skimming? physical modelling and anatomical evaluation of an unusual feeding method. Public Library of Science Biology 5: 1-9.

Jenkins, F. A., N. H. Shubin, S. M. Gatesy, and K. Padian. 2001. A diminuitive pterosaur (Pterosauria: Eudimorphodontidae) from the Greenlandic Triassic. Bulletin of the Museum of Comparative Zoology 156:131-170.

Jensen, J. A., and K. Padian. 1989. Small pterosaurs and dinosaurs from the Uncompaghre fauna (Brushy Basin Member, Morrison Formation: ?Tithonian), Late Jurassic, Western Colorado. Journal of Paleontology 63:364-373.

Ji, Q., and S.-A. Ji. 1998. A new fossil pterosaur (Rhamphorhynchoidea) from Liaoning. Jiangsu Geology 22:199-206 [Chinese].

Ji, Q., and C. Yuan. 2002. Discovery of two kinds of protofeathered pterosaurs in the Mesozoic Daohugou Biota in the Ningcheng Region and its stratigraphic and biological significances. Geological Review 48:221-224. [Chinese]

Jia, C., C. A. Forster, X. Xu, and J. M. Clark. 2007. The first stegosaur (Dinosauria, Ornithischia) from the Upper Jurassic Shishugou Formation of Xinjiang, China. Acta Geologica Sinica 81:351-356.

Kellner, A. W. A. 1994b. Remarks on pterosaur taphonomy and paleoecology. Acta Geologica Leopoldensia 39:175-189.

Kellner, A. W. A. 2003. Pterosaur phylogeny and comments on the evolutionary history of the group; pp. 105-137 in E. Buffetaut and J.-M. Mazin (eds.), Evolution and Palaeobiology of Pterosaurs. Geological Society, London, Special Publications 217.

Kellner, A. W. A. 2004. New information on the Tapejaridae (Pterosauria, Pterodactyloidea) and discussion of the relationships of this clade. Ameghiniana 41:521-534.

Kellner, A. W. A., and W. Langston, Jr. 1996. Cranial remains of Quetzalcoatlus (Pterosauria, Azhdarchidae) from the late Cretaceous sediments of Big Bend National Park, Texas. Journal of Vertebrate Paleontology 16:222-231.

Knoll, F. 2000. Pterosaurs from the Lower Cretaceous (?Berriasian) of Anoual, Morocco. Annales de Paléontologie 86:157-164.

Lü, J., and Q. Ji. 2006. Preliminary results of a phylogenetic analysis of the pterosaurs from Western Liaoning and surrounding areas. Journal of the Paleontological Society of Korea 22:239-261.

Lü, J., D. M. Unwin, L. Xu, and X. Zhang. 2008. A new azhdarchoid pterosaur from the Lower Cretaceous of China and its implications for pterosaur phylogeny and evolution. Naturwissenschaften 95:891-897.

Maddison, D. R., and W. P. Maddison, 2005. MacClade 4: Analysis of phylogeny and character evolution. Version 4.07. Sinauer Associates, Sunderland, Massachusetts.

Maisch, M. W., A. T. Matzke, and G. Sun. 2004. A new dsungaripteroid pterosaur from the Lower Cretaceous of the southern Junggar Basin, north-west China. Cretaceous Research 25:625-634.

Martill, D. M., and D. Naish, 2006. Cranial crest development in the azhdarchoid pterosaur Tupuxuara, with a review of the genus and tapejarid monophyly. Palaeontology 49:925-941.

Mazin, J.-M., J.-P. Billon-Bruyat, P. Hantzpergue, and G. Lafaurie 2003. Ichnological evidence for quadrupedal locomotion in pterodactyloid pterosaurs: trackways from the Late Jurassic of Crayssac (southwestern France); pp. 283-296 in E. Buffetaut and J.-M. Mazin (eds.), Evolution and Palaeobiology of Pterosaurs. Geological Society, London, Special Publications 217.

Newton, E. T. 1888. On the skull, brain and auditory organ of a new species of pterosaurian Scaphognathus Purdoni from the Upper Lias near Whitby, Yorkshire. Philosophical Transactions of the Royal Society of London 179:503-537.

Owen, R. 1842. Report on British Fossil Reptiles, Part II. Report of the British Association for the Advancement of Science, pp. 60-204.

Owen, R. 1859. On the vertebral characters of the Order Pterosauria, as exemplified in the Genera Pterodactylus (Cuvier) and Dimorphodon (Owen). Philosophical Transactions of the Royal Society of London 149:161-169. 
Owen R. 1870. Monograph of the fossil Reptilia of the Liassic Formations. III. Palaeontological Society, London, pp. 41-81.

Padian, K. 1983. Osteology and functional morphology of Dimorphodon macronyx (Buckland) (Pterosauria: Rhamphorhynchoidea) based on new material in the Yale Peabody Museum. Postilla 189:1-44.

Padian, K. 1984. Pterosaur remains from the Kayenta Formation (?Early Jurassic) of Arizona. Palaeontology 27:407-413.

Padian, K. 2008. The Toarcian (Early Jurassic) pterosaur Dorygnathus Wagner 1860. Palaeontology 80:1-64.

Plieninger, F. 1907. Die Pterosaurier der Juraformation Schwabens. Palaeontographica, 53:209-313.

Rjabinin, A. N. 1948. Remarks on a flying reptile from the Jurassic of the Karatau. Akademia Nauk, Palaeontological Institute, Trudy 15:86-93 [Russian].

Romer, A. S. 1956. Osteology of the Reptiles. University of Chicago Press, Chicago, Illinois, $772 \mathrm{pp}$.

Seeley, H. G. 1870. The Ornithosauria: an elementary study of the bones of pterodactyles. Deighton, Bell, and Co., Cambridge, Massachusetts, $135 \mathrm{pp}$.

Sereno, P. C. 1991. Basal archosaurs: phylogenetic relationships and functional implications. Society of Vertebrate Paleontology Memoir 2. Journal of Vertebrate Paleontology 11(4, Supplement):1-53.

Sharov, A. G. 1971. New flying reptiles from the Mesozoic of Kazakhstan and Kirghizia. Palaeontological Institute, Trudy 130:104-113 [Russian].

Stecher, R. 2008. A new Triassic pterosaur from Switzerland (Central Austroalpine, Grisons), Raeticodactylus filisurensis gen. et sp. nov. Swiss Journal of Geosciences 101:185-202.

Strong, E., and D. Lipscomb. 2000. Character coding and inapplicable data. Cladistics 15:363-371

Swofford, D. L. 2003. PAUP*. Phylogenetic Analysis Using Parsimony (*and Other Methods). Version 4. Sinauer Associates, Sunderland, Massachusetts.

Theodori, K. 1830. Knochen vom Pterodactylus aus der Liasformation von Banz. Froriep's Notizen aus dem Gebiete der Natur- und Heilkunde 19:101-103.

Unwin, D. M. 1992. The phylogeny of the Pterosauria. Journal of Vertebrate Paleontology 2(3, Supplement):57A.

Unwin, D. M. 1995. Preliminary results of a phylogenetic analysis of the Pterosauria (Diapsida: Archosauria); pp. 69-72 in A. Sun and Y. Wang (eds.), Sixth Symposium on Mesozoic Terrestrial Ecosystems and Biota, Short Papers. China Ocean Press, Beijing, China.

Unwin, D. M. 1996. The fossil record of Middle Jurassic pterosaurs. Museum of Northern Arizona Bulletin 60:291-304.

Unwin, D. M. 1997. Pterosaur tracks and the terrestrial ability of pterosaurs. Lethaia 19:373-386.

Unwin, D. M. 2002. On the systematic relationships of Cearadactylus atrox, an enigmatic Early Cretaceous pterosaur from the Santana Formation of Brazil. Mitteilungen aus dem $\mathrm{Mu}-$ seum für Naturkunde, Berlin, Geowissenschaftliche Reihe 5:239263.

Unwin, D. M. 2003a. On the phylogeny and evolutionary history of pterosaurs; pp. 138-190 in E. Buffetaut and J.-M. Mazin (eds.), Evolution and Palaeobiology of Pterosaurs. Geological Society, London, Special Publications 217.

Unwin, D. M. 2003b. Eudimorphodon and the early history of pterosaurs Rivista del Museo Civico di Scienze Naturali "Enrico Caffi" 22:39-46.

Unwin, D. M., and J. Lü. 1997. On Zhejiangopterus and the relationships of pterodactyloid pterosaurs. Historical Biology 12:199_ 210.

Viscardi, P., G. J. Dyke, M. Wilkinson, and J. M. V. Rayner. 1999. Missing data and the phylogeny of the Pterosauria. Journal of Vertebrate Paleontology 19(3, Supplement):82A.

Wagner, A. 1861. Neue Beiträge zur Kenntniss der urweltlichen Fauna des lithographischen Schiefers. 2. Schildkröten. Abhandlungen der Bayerischen Akademie der Wissenschaften, mathematischphysikalische Klasse 9:112-119.

Wang, X., D. D. A. Campos, Z. Zhou, and A. W. A. Kellner. 2008 A primitive istiodactylid pterosaur (Pterodactyloidea) from the Jiufotang Formation (Early Cretaceous), northeast China. Zootaxa 1813:1-18.

Wang, X., A. W. Kellner, Z. Zhou, and D. Campos. 2005. Pterosaur diversity and faunal turnover in Cretaceous terrestrial ecosystems in China. Nature 437:875-879.
Wang, X., A. W. Kellner, Z. Zhou, and D. Campos. 2007. A new pterosaur (Ctenochasmatidae, Archaeopterodactyloidea) from the Lower Cretaceous Yixian Formation of China. Cretaceous Research 28(2): 245-260.

Wang, X., Kellner, A. W. A., Z. Zhou, and D. A. Campos. 2008. Discovery of a rare arboreal forest-dwelling flying reptile (Pterosauria, Pterodactyloidea) from China. Proceedings of the National Academy of Science of the United States of America 105:1983-1987.

Wang, X., Z. Zhou, F. Zhang, and X. Xu. 2002. A nearly completely articulated rhamphorhynchoid pterosaur with exceptionally wellpreserved wing membranes and "hairs" from Inner Mongolia, northeast China. Chinese Science Bulletin 47:226-230.

Wellnhofer, P. 1975. Die Rhamphorhynchoidea (Pterosauria) der Oberjura-Plattenkalke Süddeutschlands. II: Systematische Beschreibung. Palaeontographica A 148:132-186.

Wellnhofer, P. 1978. Pterosauria. Handbuch der Palaeoherpetologie, Teil 19. Gustav Fischer Verlag, Stuttgart, 82 pp.

Wellnhofer, P. 1991. The Illustrated Encyclopedia of Pterosaurs. Crescent Books, New York, 192 pp.

Wild, R. 1983. A new pterosaur (Reptilia, Pterosauria) from the Upper Triassic (Norian) of Friuli, Italy. Gortania 5:45-62.

Williston, S. W. 1897. Restoration of Ornithostoma ( $i_{i}$ Pteranodon). Kansas University Quarterly, Series A 6:35-51.

Witmer, L. M. 1997. The evolution of the antorbital cavity of archosaurs: a study in soft-tissue reconstruction in the fossil record with an analysis of the function of pneumaticity. Society of Vertebrate Paleontology Memoir 3:1-73

Witton, M. P., and D. Naish. 2008. A reappraisal of azhdarchid pterosaur functional morphology and paleoecology. Public Library of Science One 3:e2271

Xu, X., and J. M. Clark. 2008. The presence of a gigantic theropod in the Jurassic Shishugou Formation, Junggar Basin, western China Vertebrata PalAsiatica 46:157-160.

Xu, X., C. A. Forster, J. M. Clark, and J. Mo. 2006a. A basal ceratopsian with transitional features from the Late Jurassic of northwestern China. Proceedings of the Royal Society B 273:2135-2140.

Xu, X., J. M. Clark, C. A. Forster, M. A. Norell, G. M. Erickson, D. A. Eberth, C. Jia, and Q. Zhao. 2006b. A basal tyrannosauroid dinosaur from the Late Jurassic of China. Nature 439:715-718

Xu, X., J. M. Clark, J. Mo, J. Choiniere, C. A. Forster, G. M. Erickson, D. W. E. Hone, C. Sullivan, D. A. Eberth, S. Nesbitt, Q. Zhao, R. Hernandez, C.-K. Jia, and Y. Guo. 2009. A Jurassic ceratosaur from China helps clarify avian digital homologies. Nature 459:940-944.

Young, C. C. 1964. On a new pterosaurian from Sinkiang, China. Vertebrata Palasiatica 8:221-256.

Young, C. C. 1973. Reports of Paleontological Expeditions to Sinkiang (II). Pterosaurian Fauna from Wuerho, Sinkiang. Memoirs of the Institute of Vertebrate Paleontology and Paleoanthropology. Academica Sinica 11:18-35.

Submitted January 27, 2006; accepted May 2, 2009

APPENDIX 1. Description of characters used in phylogenetic analysis of Sericipterus wucaiwanensis, gen. et sp. nov., and relationships of basal pterosaurs. Characters are polarized with respect to Ornithosuchus longidens Huxley, 1877, Herrerasaurus ischigualastensis Reig, 1963, and Scleromochlus taylori Woodward, 1907, as outgroups. All characters are unordered and equally weighted. Characters are cited after the analysis to use the most similar character.

(1) Skull anterior margin, shape (Maisch et al. 2004): blunt (0); rostral process (1).

(2) Rostral process cross-section, shape (new character): triangular (0), elliptical (1).

(3) Skull dorsal margin, curvature exclusive of cranial crests (Unwin, 2003a): straight (0); convex (1)

(4) Skull ventral margin at jaw articulation, curvature (Unwin, 2003a): straight (0); concave (1).

(5) Rostrum, shape (Andres and Ji, 2008): laterally compressed (0); dorsoventrally depressed (1); anteroposteriorly compressed (2). 
(6) Rostrum anterior end, lateral width (after Kellner, 2003): tapered (0); expanded (1).

(7) Premaxillary crest (Bennett, 1994): absent (0); present (1).

(8) Premaxillary bar, width (Kellner, 2003): wide (0; narrow (1).

(9) Premaxilla posterior margin, position (Unwin, 1995): anterior to frontals (0); between frontals (1).

(10) External naris dorsal and ventral margins, orientation (new character): acute angle (0), subparallel (1).

(11) External naris/nasoantorbital fenestra, position relative to premaxillary tooth row (Kellner, 2003): dorsal (0); posterior (1).

(12) External naris and antorbital fenestra, configuration (Unwin, 1995): separate (0); confluent (1).

(13) Antorbital fenestra ventral margin, position relative to external naris ventral margin (Unwin, 2003b): same level (0); ventral (1).

(14) Antorbital/nasoantorbital fenestra, length relative to height (Unwin, 2003b): less than twice height (0); at least twice height (1).

(15) Antorbital/nasoantorbital fenestra dorsal and ventral margins, orientation (new character): acute angle (0); subparallel (1).

(16) Orbit, length relative to antorbital/nasoantorbital fenestra length (after Unwin, 1995): at most antorbital/nasoantorbital fenestra length $(0)$; more than antorbital/nasoantorbital fenestra length (1).

(17) Maxilla-nasal contact, position (after Unwin, 2003a): on main body of nasal (0); on bar between external naris and antorbital fenestra (1).

(18) Jugal ascending process, orientation (new character): anterodorsal (0), dorsal (1).

(19) Jugal posterior process, orientation (new character): posterior (0), ventral (1).

(20) Quadrate, orientation relative to ventral margin of skull (Unwin, 1995): subvertical (0); inclined (1).

(21) Mandible articulation condyles, orientation (after Bennett, 1994): parasagittal (0); oblique (1).

(22) Mandible articulation, position (after Kellner, 2003): posterior to middle of orbit (0); under or anterior to middle of orbit (1).

(23) Palatal elements (Unwin, 2003b): broad and flat (0); thin bars of bone (1).

(24) Maxilla and internal naris, configuration (Kellner, 2003): maxilla contacts internal naris $(0)$; maxilla excluded from internal naris (1).

(25) Mandibular symphysis fused (Unwin, 1995): absent (0); present (1).

(26) Mandibular symphysis, length relative to mandible length (Unwin, 1995): less than 30\% mandible length (sym/ma < 0.30) $(0)$; at least $30 \%$ mandible length $(\mathrm{sym} / \mathrm{ma} \geq 0.30)(1)$.

(27) Dentary, lateral length relative to mandible length (Unwin, 1995): at most three-fourths mandible length (de/ma $\leq 0.75)(0)$; more than three-fourths mandible length $(\mathrm{de} / \mathrm{ma}>0.75)$.

(28) Mandible anterior end, orientation (after Kellner, 2003): anterior (0); anterodorsal (1); anteroventral (2).

(29) Mandibular rami dorsal margin, shape (Unwin, 2003a): dorsal eminence present (0); flat (1).

(30) Jaw margins, shape (new character): straight (0); undulating (1).

(31) Teeth, variation in shape (Unwin, 2003b): isodont (0); heterodont (1).

(32) Teeth, maximum curvature (after Andres and Ji, 2008): horizontal displacement of curvature less than tooth di- ameter (0); horizontal displacement of curvature at least tooth diameter (1).

(33) Teeth, curvature orientation (new character): posterior (0); lingual (1).

(34) Teeth, maximum crown height (after Andres and Ji, 2008): less than four times tooth diameter (0); at least four times tooth diameter (1).

(35) Teeth, size variation (after Unwin, 2003b): even transition along tooth row (0); sharp disparity between mesial and distal teeth (1).

(36) Teeth, vertical orientation (after Andres and Ji, 2008): all teeth upright (0); procumbent teeth present (1).

(37) Teeth, lateral orientation (after Unwin, 2002): upright (0); ventrolateral (1).

(38) Teeth, texture (new character): flat (0); fluted teeth present (1); teeth with sharp mesial and distal keels (2).

(39) Cheek teeth, shape (after Andres and Ji, 2008): recurved, labiolingually compressed and recurved apically (0); triangular in outline with cuspules (1); slender (2); sharp and conical (3).

(40) Cheek teeth, spacing relative to successive teeth diameters (Andres and Ji, 2008): less than successive teeth diameters $(0)$; at least successive teeth diameters (1).

(41) Maxillary teeth, position of largest teeth (new character): middle of maxilla (0); mesial (1).

(42) Rostral teeth, number (after Unwin, 2003a): more than 22 teeth (0); at most 22 teeth (1).

(43) Rostral tooth row anterior margin, position (after Kellner, 2003): anterior skull margin (0); does not reach anterior skull margin (1).

(44) Mandibular tooth row anterior margin, position (Andres and $\mathrm{Ji}, 2008)$ : anterior mandible margin (0); does not reach anterior mandible margin (1).

(45) Mid-cervical vertebrae, neural arch, lateral pneumaticity (new character)

(46) Mid-cervical ribs, shape (Unwin, 1995): elongate (0); reduced (1).

(47) Combined dorsal and sacral vertebral series, length relative to ulna length (Unwin, 2003b): longer than ulna length (0); at most ulna length (1).

(48) Caudal vertebrae, number (Kellner, 2003): more than 15 (0); at most 15 (1).

(49) Caudal zygapophyses, length (Unwin, 2003b): short (0); extremely elongate (1).

(50) Sternum shape (after Unwin, 2003b): narrow (0); rectangular (1); semicircular (2); triangular (3).

(51) Humerus, length relative to metacarpal IV length (Kellner, 2003): at least two-and-one-half times metacarpal IV length (hu/McIV $\geq 2.50)$ (0); between one-and-one-half and two-and-one-half times metacarpal IV length $(1.50$ $<\mathrm{hu} / \mathrm{McIV}<2.50)(1)$; at most one-and-one-half times metacarpal IV length $(\mathrm{hu} / \mathrm{McIV}<2.50)(2)$.

(52) Humerus, length relative to femur length (after Kellner, 2003): less than one-and-one-half times femur length $(\mathrm{hu} / \mathrm{fe}<1.50)(0) ;$ at least one-and-one-half times femur length (hu/fe $\geq 1.50)(1)$.

(53) Humerus proximal end, shape in dorsal view (Unwin, 2003b): symmetric profile (0); angular, sub-symmetric profile (1).

(54) Humerus deltopectoral crest, shape (after Kellner, 2003): proximal expansion of humeral shaft (0); anteroposteriorly tall and curved proximally (1); proximodistally elongate and subrectangular (2); anteroposteriorly tall and oblong with a middle constriction (3); anteroposteriorly tall with rounded anterior margin (4); 
proximodistally elongate with a round proximal expansion (5).

(55) Ulna, length relative to humerus length (Unwin, 2003b): less than one-and-one-half times humerus length $(\mathrm{ul} / \mathrm{hu}$ $<1.50)(0)$; at least one-and-one-half times humerus length ( $\mathrm{ul} / \mathrm{hu} \geq 1.50)(1)$.

(56) Ulna, length relative to tibia length (Unwin, 1995): at most tibia length $(\mathrm{ul} / \mathrm{ti} \leq 1.00)(0)$; longer than tibia length (ul/ti > 1.00) (1).

(57) Pteroid, length relative to ulna length (Bennett, 2007): at most one-sixth ulna length $(\mathrm{pt} / \mathrm{ul} \leq 0.17)(0)$; more than one-sixth ulna length $(\mathrm{pt} / \mathrm{ul}>0.17)(1)$

(58) Metacarpals I-III, relative lengths (Unwin, 1995): disparate (0); subequal (1).

(59) Manual digit IV, length relative to total forelimb length (Unwin, 2003b): less than $65 \%$ total forelimb length $(\mathrm{dIV} /$ forelimb $<0.65)(0)$; at least $65 \%$ total forelimb length (dIV/forelimb $\geq 0.65)(1)$.

(60) Manual unguals, size relative to pedal unguals (Unwin, 2003a): less than twice pedal ungual sizes (0); at least twice pedal ungual sizes (1).

(61) First phalanx of manual digit IV, length relative to total digit IV length (Unwin, 2003b): first phalanx less than $35 \%$ total digit IV length (f1dIV/dIV < 0.35) (0); first phalanx at least $35 \%$ total digit IV length (f1dIV/dIV $\geq$ 0.35) (1).

(62) First phalanx of manual digit IV, length relative to tibia length (Andres and Ji, 2008): less than one-and-one-third tibia length $(\mathrm{fldIV} / \mathrm{ti}<1.33)(0)$; at least one-and-onethird tibia length (f1dIV/ti $\geq 1.33)$ (1).

(63) Second phalanx of manual digit IV, length relative to first phalanx length (after Kellner, 2003): at least first phalanx of digit IV length (f2dIV/f1dIV $\geq 1.00)(0)$; less than first phalanx of digit IV length (f2dIV/f1dIV < 1.00) (1).

(64) Second phalanx of manual digit IV, length relative to ulna length (Unwin, 2003b): less than ulna length $(\mathrm{f} 2 \mathrm{dIV} / \mathrm{ul}<1.00)(0)$; at least ulna length $(\mathrm{f} 2 \mathrm{dIV} / \mathrm{ul} \geq$ 1.00) (1).

(65) Third phalanx of manual digit IV, length relative to first phalanx length (after Kellner, 2003): at least first phalanx length (f3dIV/f1dIV $\geq 1.00)(0)$; less than first phalanx length $(\mathrm{f} 3 \mathrm{dIV} / \mathrm{f} 1 \mathrm{dIV}<1.00)(1)$

(66) Third phalanx of manual digit IV, length relative to second phalanx length (after Kellner, 2003): at least second phalanx length (f3dIV/f2dIV $\geq 1.00)(0)$; less than second phalanx length (f3dIV/f2dIV < 1.00) (1).

(67) Anterior iliac process, length relative to posterior iliac process length (Unwin, 2003b): at most posterior process length (0); longer than posterior process length (1).

(68) Ischiopubic plate, shape (Unwin, 2003b): unexpanded (0); expanded (1).

(69) Prepubis, length relative to width (Unwin, 2003b): greater than width (0) at most width (1).

(70) Femur, length relative to metacarpal IV length (after Kellner, 2003): at least twice metacarpal IV length (fe/mcIV $\geq 2.00)(0)$; less than metacarpal IV length $(\mathrm{fe} / \mathrm{mcIV}<2.00)(1)$

(71) Fibula, length relative to tibia length (Unwin, 2003a): at least $80 \%$ tibia length ( $\mathrm{fi} / \mathrm{ti} \geq 0.80)(0)$; less than $80 \%$ tibia length $(\mathrm{fi} / \mathrm{ti}<0.80)(1)$

(72) Metatarsal III, length relative to tibia length (after Kellner, 2003): more than one-third tibia length ( $\mathrm{mtIII} / \mathrm{ti}>$ $0.33)(0)$; at most one-third tibia length $(\mathrm{mtIII} / \mathrm{ti} \leq 0.33)$ (1).

(73) Metatarsal IV, length relative to metatarsal III length (after Unwin, 1995): subequal to metatarsal III length (0); shorter than metatarsal III length (1).
(74) Pedal digit V, number of phalanges (Kellner, 2003): four (0); two (1); at most one (2).

(75) Pedal digit V ultimate phalanx, shape (after Kellner, 2003): straight (0); curved (1).

APPENDIX 2. Character-taxon matrix used for the phylogenetic analysis of Sericipterus wucaiwanensis, gen. et sp. nov., and the relationships of the basal pterosaurs.

Ornithosuchus longidens

0-0000000? 000?000000 00000??000 00000000000000000000 000000-000 ?0????00-0 00000

Herrerasaurus ischigualastensis 0-00000000 $00100000000000000000000000000000000 ? 000$ ? 000000-000 00_-00-000020

Scleromochlus taylori 0-??000?0? ?0?1?1??0? ?0000000?0 000?000??? ?00??0000? 000000-10? ??????10-0 0002-

\section{Preondactylus buffarinii}

0-000000?0 10000?1000 ?0??0000001000100010 0000?00?0? $100100100000000000 ? 0000 ? ?$

Eudimorphodon ranzii

0-000000001000010001?00?00120010001101100001000?01 10020?10?1 ???????001 ?????

Austriadactytlus cristatus 0-0?001000 10000100?0 ?0??????00 1001100110 000??0?00? ????0????1 0?0100???? ?????

Peteinosaurus zambelli ?????????? ?????????? ????0?1?00 1000??0010 ??????001? 1001001001001000100000010

Dimorphodon macronyx 0-10000000 10000010?0?00?0010000000100001000000001? 1001001001000000010011010

Campylognathoides liasicus 0-000000101000010001000100121000000000011001000011 1002011011010111111110111

Sericipterus wucaiwanensis, gen. et sp. nov. 1101011011101 ?0???11 10????1?11 $0111011221111 ? 1 ? ? ? ? ?$ ??03???????1?00?1?? ?????

Angustinaripterus longicephalus 11010110?1 1011000011 ?0??101111 $0111011221111 ? ? ? ? ? ?$ ????????? ?????????? ?????

Harpactognathus gentryii

10??1110?1 101?0????? ??01?????1 0???0?1?21 111???????

?????????? ?????????? ?????

Cacibupteryx caribensis

??010?0011 1011110001 ?001?????0 0?????0??1 11????????

?????????? ?????????? ?????

Rhamphorhynchus muensteri

$100100001110111100 ? 111011111100101010221111110001\{12\}$ 1003111111011111111110111

Dorygnathus banthensis

0-01000011 1011010001100110111001010100211101100013 1003110101000001111110111

Scaphognathus crassirostris

0-01000010101001000100011010100001000021 1100000012 1003110101000001111110111 
Sordes pilosus

0-01000010 $10000101 ? 1000110101000000000311100100012$ 0004111101000001111011111

Jeholopterus ningchengensis

0-1?200110 01-001-??? ?01000?0?0 0000000031 1100?1110? 0111010101111011111010010

Dendrorhynchoides curvidentatus

0-1?2001?0 0????????? ??1????0?0 00000??031 ?????1110? $01140101 ? 1 ? 111111 ? ? 010010$
Batrachognathus volans

0-1?200110 01-001-??? ?0100010?0 0000000031 1100?10??2 011411?1?1 ????????0 10???

Anurognathus ammoni 0-1?200110 0????1?10? 00100010?0 0000000031 110001\{01\}100 $001401010111101111 ? 010010$

Pterodactyloidea

0-01000010 11-100-1?1 010111101000000000311000010102 $200500110\{01\} 0\{01\} 1\{01\} 11111111120$ 